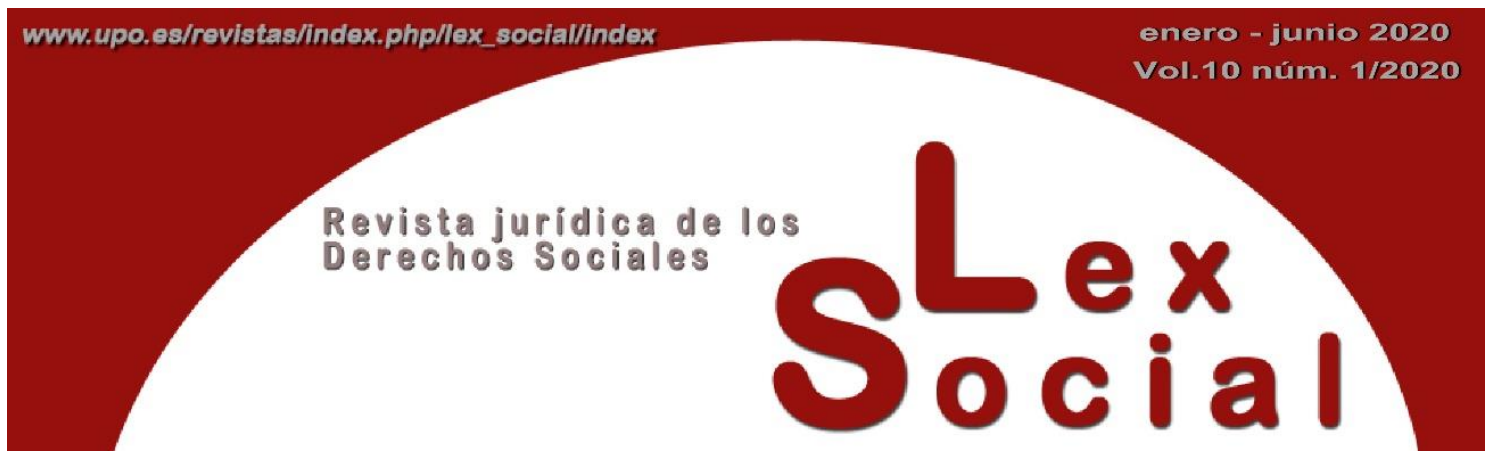

\title{
LOS DERECHOS SOCIALES DE LA JUVENTUD: EL PAPEL DE LAS ENTIDADES LOCALES Y REGIONALES ${ }^{1}$
}

\section{LES DROITS SOCIAUX DES JEUNES: LE RÔLE DES POUVOIRS LOCAUX ET RÉGIONAUX}

\section{SOCIAL RIGHTS OF YOUNG PEOPLE: THE ROLE OF LOCAL AND REGIONAL AUTHORITIES}

\author{
LUIS JIMENA QUESADA \\ Catedrático de Derecho Constitucional \\ Universitat de València
}

\begin{abstract}
${ }^{1}$ El presente trabajo de investigación, con sus anexos (traducidos al español por el propio autor), tienen su origen en el contrato de servicios (servicios intelectuales) suscrito por el autor como experto con el Congreso de Poderes Locales y Regionales del Consejo de Europa en marzo de 2018 (referencia: MMS: 2018-223, PO 582522) para la redacción del informe "Assurer l'exercice des droits sociaux des jeunes: le rôle des pouvoirs locaux et régionaux", y que ha dado lugar a la Resolución 442(2019) y a la Recomendación 433(2019) de dicho Congreso, así como a la exposición de motivos o memorando explicativo común a ambas. En concreto, el informe (apartados 1 a 4 del presente trabajo) fue redactado por el autor en francés (y traducido por el Consejo de Europa a la otra lengua oficial, el inglés) e integra literalmente dicha exposición de motivos (tal como se indica en ella a pie de página), de la que podrá comprobarse que se extrae asimismo el contenido de las citadas Resolución y Recomendación (apartado 5 del presente trabajo). El autor compareció para la explicación y debate sobre el borrador y la versión definitiva del informe ante la Comisión de Asuntos de Actualidad (Current Affairs Committee/Commission des questions d'Actualité) del Congreso en Estrasburgo en sendas sesiones de 19 de junio y de 6 de noviembre de 2018, antes de su adopción final por el Pleno en sesión de 3 de abril de 2019. Las versiones oficiales de la Resolución, de la Recomendación y de la exposición de motivos pueden leerse en los siguientes enlaces: en francés (https://rm.coe.int/les-droits-sociaux-des-jeunes-le-role-des-pouvoirslocaux-et-regionaux/1680932eb0) y en inglés (https://rm.coe.int/social-rights-of-young-people-the-role-oflocal-and-regional-authoriti/1680932eaf). Por lo demás, el autor quiere dejar constancia de su agradecimiento a Jean-Michel Belorgey (Ex Presidente del Comité Europeo de Derechos Sociales) y a Régis Brillat (Ex Secretario Ejecutivo de dicho Comité), cuyas ideas permitieron enriquecer el primer borrador del informe, así como a Muriel Grimmeissen (Co-secretaria de la Comisión de Asuntos de Actualidad del Congreso), por su cualificada asistencia para la redacción y presentación de la versión final del informe. Por otra parte, no está de más recordar que esta actividad de transferencia vino respaldada por otra previa, en particular por el contrato de servicios suscrito igualmente por el autor como experto con el mismo Congreso de Poderes Locales y Regionales en octubre de 2016 (referencia. 2016-719, PO 522075, FIMS 27426) para asistencia al debate temático (y redacción del correspondiente informe de conclusiones) celebrado en dicho Congreso el 20 de octubre de 2016 bajo el título "Droits sociaux en Europe: la mise en œuvre de la Charte sociale européenne au niveau régional"). Por último, el autor también desea hacer constar que el presente trabajo se inscribe en el espíritu del "Proceso de Turín" para la promoción de la Carta Social Europea y se ha elaborado en el marco del Grupo de Investigación "Derechos Humanos y Carta Social Europea" de la Universitat de València (referencia: GIUV 2013-148, Directora: Prof ${ }^{\mathrm{a}}$ Carmen Salcedo Beltrán).
\end{abstract}


Artículo recibido el 2 de noviembre de 2019

Artículo aceptado el 7 de noviembre de 2019

\section{RESUMEN}

En el marco de toda una serie de debates, resoluciones y otros instrumentos tendentes a fortalecer la integración, participación y compromiso de la juventud a nivel local y regional, este artículo pone el acento en los derechos sociales de los jóvenes garantizados por la Carta Social Europea. Subraya el papel esencial de los entes locales y regionales, en virtud de sus competencias en el ámbito social, para facilitar el acceso y el ejercicio efectivo de los derechos sociales por parte de los jóvenes; a tal efecto, se pone el énfasis en el cumplimiento de la Carta Social y su jurisprudencia como fuentes de inspiración para la acción local y regional en este terreno. El artículo hace un llamamiento a los entes territoriales para alentar a sus autoridades nacionales a firmar y ratificar la Carta Social Europea revisada y aceptar el procedimiento de reclamaciones colectivas. También les invita a difundir el texto de la Carta Social a través de sus propios canales de comunicación y redes sociales, así como a sensibilizar sobre los derechos sociales de los jóvenes a través de diversas iniciativas. Para los gobiernos de los Estados miembros, propone desarrollar y coordinar sus acciones de concienciación sobre los derechos sociales de los jóvenes con los otros niveles de gobernanza y los gobiernos de los Estados Partes en la Carta Social, involucrando a los gobiernos locales y regionales en todo el proceso de implementación de este instrumento jurídico.

Palabras Clave: Entidades locales y regionales, Carta Social Europea, Comité Europeo de Derechos Sociales, Proceso de Turín.

\section{RÉSUMÉ}

Dans le cadre de tout une série de débats, de résolutions et d'autres instruments pour renforcer l'intégration, la participation et l'engagement des jeunes aux niveaux local et régional, le présent article met l'accent sur les droits sociaux des jeunes garantis par la Charte sociale européenne. Il souligne le rôle essentiel des pouvoirs locaux et régionaux, en vertu de leurs compétences dans le domaine social, pour faciliter l'accès et l'exercice effectif des droits sociaux par les jeunes, la mise en œuvre de la Charte sociale et de sa jurisprudence constituant une source d'inspiration pour mener des actions locales et régionales dans ce domaine. L'article appelle les collectivités territoriales à encourager leurs autorités nationales à signer et ratifier la Charte sociale européenne révisée et à accepter la procédure de réclamations collectives. Il les invite aussi à diffuser le texte de la Charte sociale par leurs propres canaux de communication et les réseaux sociaux, et de sensibiliser aux droits sociaux des jeunes par diverses initiatives. Aux gouvernements des États membres, il propose de développer et de coordonner leurs actions de sensibilisation aux droits sociaux des jeunes avec les autres niveaux de gouvernance et aux Gouvernements des États parties à la Charte sociale, et d'impliquer les collectivités locales et régionales tout au long de la mise en œuvre de cet instrument juridique. 
Mots Clés: Jeunesse, Pouvoirs locaux et régionaux, Charte sociale européenne, Comité européen des Droits sociaux, Processus de Turin.

\begin{abstract}
In the framework of a series of debates, resolutions and other instruments to strengthen the integration, participation and engagement of young people at the local and regional levels, this essay focuses on the social rights of young people guaranteed by the European Social Charter. It underlines the essential role that local and regional authorities play by virtue of their competences in the social field, in facilitating the access and effective exercise of social rights by young people, the implementation of the Social Charter and its jurisprudence being a source of inspiration for local and regional to take action in this field. The paper calls on local and regional authorities to encourage their national authorities to sign and ratify the revised European Social Charter and to accept the collective complaints procedure. It also invites them to disseminate the text of the Charter through their own communication channels and social networks, and raise awareness of the social rights of young people through various initiatives. To the governments of member states, it proposes to develop and coordinate actions with other levels of governance and governments of the States Parties to the Charter, to raise awareness of young people's social rights and to involve local and regional authorities throughout the implementation of this legal instrument.
\end{abstract}

KEYWORDS: Young People, Local and Regional Authorities, European Social Charter, European Committee of Social Rights, Turin Process.

SUMARIO

1. INTRODUCCIÓN

2. DERECHOS SOCIALES MÁS ESTRECHAMENTE RELACIONADOS CON LA JUVENTUD EN EL MARCO DE UN ENFOQUE INTEGRADO

2.1 La posición crucial de la Carta Social Europea

2.2. La voz de la juventud y el trabajo previo del Congreso de Poderes Locales y Regionales

2.3. La naturaleza subsidiaria del Convenio Europeo de Derechos Humanos

2.4. La naturaleza complementaria de las acciones de la Unión Europea

3. PROBLEMAS Y BUENAS PRÁCTICAS RELACIONADAS CON EL ACCESO JUVENIL A LOS DERECHOS SOCIALES A NIVEL LOCAL Y REGIONAL

3.1. Derechos sociales de la juventud y aspectos multifactoriales 
3.2. Buenas prácticas "convencionales" para la promoción de ciertos derechos sociales (salud) adaptándose a las fórmulas "modernas" de acceso juvenil

3.3. Buenas prácticas "más generales" centradas en el acceso de la juventud a los derechos sociales

3.4. Medios modernos de acceso a los derechos sociales y heterogeneidad de la juventud en términos de educación

3.5. Acceso de la juventud a la educación

3.6. Acceso de la juventud al mercado laboral

3.6.1. Crisis económica y precarización laboral de la juventud

3.6.2. Evitar que la crisis económica se convierta en una crisis de valores en la juventud

3.6.3. Buenas prácticas y colaboración de los entes territoriales

3.7. Acceso de la juventud a la vivienda

3.7.1. En general

3.7.2. Situaciones de vulnerabilidad

3.8. La lucha contra la discriminación basada en el género y otros estereotipos discriminatorios en la juventud

3.9. Un desafio: mejorar el acceso a los derechos sociales y combatir el no recurso o la dificultad para recurrir

\section{CONCLUSIONES}

5. ANEXOS.

5.1. Resolución 442(2019) del Congreso de Poderes Locales y Regionales.

5.2 Recomendación 433(2019) del Congreso de Poderes Locales y Regionales.

\section{INTRODUCCIÓN²}

1. La Carta Social Europea (STE No 163, en adelante la "Carta Social") fue abierta a la firma de los Estados miembros del Consejo de Europa en 1961, entró en vigor en 1965 y fue revisada en 1996. Se trata de un documento clave que establece las reglas básicas para los derechos sociales y económicos fundamentales a nivel paneuropeo. Garantiza una amplia gama de derechos humanos cotidianos relacionados con el empleo, la vivienda, la

\footnotetext{
${ }^{2}$ La presente Exposición de Motivos o Memorando Explicativo se basa en el documento redactado por Luis Jimena Quesada, Catedrático de Derecho Constitucional (Universidad de Valencia, España) y ex Presidente del Comité Europeo de Derechos Sociales.
} 
salud, la educación, la protección social y el bienestar. Dicho lo cual, en el plano de su cumplimiento, siguen siendo necesarias pautas concretas para sugerir el modo en que las autoridades nacionales, locales y regionales pueden aplicar estas reglas.

2. Una serie de textos adoptados por el Consejo de Europa en el curso de la última década que dirigen recomendaciones a los Estados miembros ha puesto de manifiesto la responsabilidad de las autoridades públicas para facilitar el acceso de la juventud a los derechos fundamentales.

3. Las recomendaciones de la Asamblea Parlamentaria del Consejo de Europa "El acceso de la juventud a los derechos fundamentales" (2015 (2013)) y "Hacia una Convención Marco Europea sobre los Derechos de la Juventud" (1978 (2011)) ${ }^{3}$, así como la Recomendación del Comité de Ministros CM/Rec(2016)7 a los Estados miembros sobre "El acceso de los jóvenes a los derechos ", adoptada el 28 de septiembre de 2016, brindaron la oportunidad de subrayar que no resulta necesario adoptar un tratado específico sobre los derechos de los jóvenes, sino más bien explotar los instrumentos vinculantes ya existentes y tomar medidas para facilitar el acceso de los jóvenes a los derechos fundamentales consagrados en el Convenio Europeo de Derechos Humanos. (en adelante, el "CEDH") y en la Carta Social revisada.

4. En lo que atañe a la juventud, el Congreso de Poderes Locales y Regionales del Consejo de Europa (en adelante "el Congreso") se centró inicialmente en su participación en la vida local y regional y en las políticas de juventud /trabajo juvenil a nivel local y regional para apoyar la transición de los jóvenes hacia la autonomía y la vida profesional, así como para empoderar a los jóvenes de los barrios o de los grupos desfavorecidos tales como los pertenecientes a la etnia gitana ${ }^{4}$.

5. El cumplimiento de los derechos sociales de los jóvenes a nivel local y regional forma parte del programa de trabajo del Congreso desde la presentación en 2015 por los Delegados jóvenes del Congreso de una propuesta de resolución sobre "la promoción por parte de las autoridades locales y regional del acceso de los jóvenes a los derechos sociales", con ocasión de la $29^{a}$ sesión del Congreso, pidiendo que se examinaran medidas dirigidas a facilitar el acceso de los jóvenes a sus derechos ${ }^{5}$. Hicieron notar que “...el acceso a una educación de calidad, un empleo seguro, condiciones de vida dignas,

\footnotetext{
${ }^{3}$ La Recomendación de la Asamblea Parlamentaria 1978(2011) "Hacia una Convención Marco Europea sobre los Derechos de la Juventud" brindó la oportunidad para una reflexión interesante que confirmó que no resulta necesario adoptar un tratado específico sobre los derechos de la juventud, sino más bien explotar los instrumentos vinculantes ya existentes en la Organización: su principio 7.1 invita a los Estados Miembros a "tomar medidas que faciliten el acceso de la juventud a los derechos fundamentales consagrados en el Convenio Europeo de Derechos Humanos y en la Carta Social Europea (revisada)".

${ }^{4}$ Resolución 386(2015) "Adoptar un lenguaje común entre la juventud y las entidades locales para eliminar las barreras a la participación juvenil", Recomendación 128(2003) "La Carta Europea Revisada sobre la Participación de los Juventud en la Vida Local y Regional", Resolución 366(2014) "Empoderar a la juventud de etnia gitana a través de la participación: diseñar políticas efectivas a nivel local y regional". ${ }^{5}$ Proposición CG/2015(29)23, 20 de octubre de 2015.
} 
transportes, atención sanitaria, tecnologías y oportunidades de participación social, cultural y económica constituyen condiciones previas para la inclusión y la ciudadanía activa de todos los jóvenes".

6. En 2016, el debate organizado por la Cámara de las Regiones sobre los "Derechos sociales en Europa: el cumplimiento de la Carta Social Europea a nivel regional", enfatizó el lugar necesario y esencial de los entes locales y regionales para dotar de efectividad a los derechos reconocidos por la Carta Social.

7. El presente informe se inscribe en el espíritu del "Proceso de Turín" (profundizando la subsidiariedad y la dimensión social de los pilares del Consejo de Europa mediante el fortalecimiento de la Carta Social a nivel local y regional, sin olvidar las sinergias con la Unión Europea) $)^{6}$, así como en una de las prioridades del Congreso adoptadas para 20172020 "Construyendo sociedades inclusivas". Responde asimismo a las preocupaciones de los Delegados jóvenes para fortalecer la capacidad de la juventud a la hora de ejercer sus derechos ${ }^{7}$. Los Delegados jóvenes también contribuyeron en los debates desarrollados en las reuniones del Comisión sobre las cuestiones de actualidad del Congreso en 2018, y posteriormente en la reunión plenaria de la 36 a sesión del Congreso, en abril de 2019, cuando se aprobó este informe.

8. El énfasis en los derechos establecidos en la Carta Social que afectan particularmente a la juventud tiene dos consecuencias:

a. En primer lugar, la Carta Social es el tratado europeo de derechos sociales por excelencia que se erige en la base jurídica esencial para la participación de los jóvenes en la vida social. El objetivo es, por lo tanto, darlo a conocer a la juventud y explotarlo en la práctica, en lugar de insistir en la elaboración de un instrumento europeo específico sobre sus derechos.

b. En segundo lugar, en el curso de los trabajos que han pretendido fortalecer la promoción y protección de los derechos cubiertos (explícitamente o no) por la Carta Social y otros instrumentos del Consejo de Europa en el marco de un enfoque integrado, los propios jóvenes han convenido en el seno del Consejo de Europa en que existen problemas prácticos referentes al acceso y al ejercicio de sus derechos sociales.

9. En este contexto, teniendo en cuenta los trabajos preliminares del Congreso y del Sector de la Juventud del Consejo de Europa en este campo, el presente informe apunta a proporcionar ejemplos de buenas (o malas) prácticas, así como recomendaciones. especialmente extraídas de la experiencia en el cumplimiento de la Carta Social.

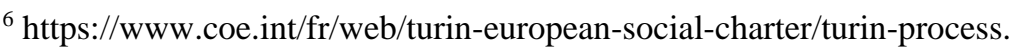

${ }^{7}$ Proposición de los delegados jóvenes para el desarrollo de un conjunto de herramientas para las entidades locales, destinado a facilitar el acceso de la juventud a sus derechos, CG31(2016)18, 20 de octubre de 2016. ISSN: 2174-6419 Lex Social, vol. 10, núm. 1 (2020)
} 


\section{DERECHOS SOCIALES MÁS ESTRECHAMENTE RELACIONADOS CON LA JUVENTUD EN EL MARCO DE UN ENFOQUE INTEGRADO}

\subsection{La posición crucial de la Carta Social Europea}

10. La Carta Social menciona explícitamente a la juventud como beneficiaria o titular de derechos sociales con respecto a la educación y la inserción en el mercado laboral (orientación y formación profesionales, artículos 9 y 10) o asistencia a los jóvenes hogares (protección económica, jurídica y social de la vida familiar, artículo 16).

11. En cualquier caso, los jóvenes disfrutan implícitamente de los otros derechos garantizados por la Carta Social (y por la jurisprudencia del Comité Europeo de Derechos Sociales -en adelante, el CEDS) en el marco de los dos mecanismos de control: el sistema de informes y el procedimiento de reclamaciones colectivas en el ámbito laboral (artículo 1), de salud (artículo 11), de la seguridad social (artículo 12), de la asistencia social y médica (artículo 13) o del acceso a los servicios sociales (artículo 14).

12. Además, el Comité ha abordado bajo el ángulo de la Carta Social situaciones de vulnerabilidad que afectan a la juventud, tales como la discriminación por razón de edad en materia de remuneración (artículo 4) y la dimensión de género (artículo 20), el estatuto de los jóvenes con discapacidad (artículo 15) o los jóvenes migrantes (artículos 18 y 19), o la protección de los jóvenes contra la pobreza y la exclusión social (artículo 30) y el acceso a la vivienda social (artículo 31).

13. Ciertamente, ha habido aspectos que, pese a no estar explícitamente previstos en la Carta Social (incluida la de 1961), fueron no obstante objeto de debate en el curso de los trabajos preparatorios (por ejemplo, se abogó por hacer que la educación universitaria sea progresivamente gratuita e introducir un "pre-salario" para los estudiantes) ${ }^{8}$ y se han seguido debatiendo en aras de su reconocimiento formal en el texto del tratado (por ejemplo, la propuesta en 2003 del Protocolo adicional a la Carta Social Revisada relativo al derecho a la educación superior).

14. Sea como fuere, la ausencia de disposiciones que extiendan explícitamente este ámbito de aplicación material de la Carta Social no ha socavado la concepción del tratado como un "instrumento vivo", al considerarse que la educación superior ya está cubierta por el artículo 10 de la Carta Social y que los jóvenes mayores de 18 años deben tener asimismo la posibilidad (en virtud del artículo 13) de acceder a una renta mínima vital para vivir de manera autónoma (entre otras, las Resoluciones de la Asamblea Parlamentaria 1885(2012) "La joven generación sacrificada: repercusiones sociales, económicas y políticas de la crisis financiera" y 2197(2018) "Una renta mínima de ciudadanía, una idea que se abre paso"). En su Resolución 1885(2012), la Asamblea

\footnotetext{
8 Recueil des travaux préparatoires de la Charte sociale européenne, Vol. II (1955): https://www.coe.int/fr/web/turin-european-social-charter/preparatory-work, p. 28 y p. 34. 
observó en particular que hay cada vez más jóvenes que no son estudiantes, ni empleados, ni están formándose (llamados “ninis" o generación “nini” en español o NEETS en inglés: "Not in Education, Employment or Training") y que dependen en gran medida de la solidaridad familiar. Ahora bien, tal como se indica en el informe explicativo de la Resolución 2197(2018) ${ }^{9}$, los dispositivos europeos destinados a garantizar una renta mínima deberían contribuir a una mejor integración de estos jóvenes en la sociedad, puesto que ello es también una obligación derivada de los artículos 13 y 14 de la Carta Social.

15. En estos ámbitos, particularmente precarios en el contexto de la crisis económica y financiera de la última década (por ejemplo, el aumento del número de jóvenes desempleados o las dificultades de acceso a la educación superior a causa de la reducción de las becas o del incremento de las tasas de matrícula), la Carta Social como instrumento jurídico vinculante compensa las restricciones.

\subsection{La voz de la juventud y el trabajo previo del Congreso de Poderes Locales y Regionales}

16. Además del tratado emblemático del Consejo de Europa sobre derechos sociales (y el lugar de la juventud en dicho tratado), y en relación de complementariedad con las acciones de otras instituciones del Consejo de Europa (Asamblea Parlamentaria, Comité de Ministros, Sector de la Juventud, etc.), el Congreso ha producido varios textos sobre el acceso de los jóvenes a los derechos (en general y/o más precisamente a los derechos sociales) desde el punto de vista de la gobernanza local y regional ${ }^{10}$.

17. En la Resolución 296(2010) sobre el "Papel de las autoridades locales y regionales en el cumplimiento de los derechos humanos", el Congreso subrayó la importancia de las decisiones tomadas por los entes territoriales, teniendo en cuenta sus competencias, "especialmente en materia de educación, vivienda, salud, medio ambiente o mantenimiento del orden", así como para "garantizar la igualdad de acceso a los servicios públicos para todos, ciudadanos y no ciudadanos, sin discriminación respeto a ninguna persona y velando por la preservación de los derechos sociales ", confiriéndoles un lugar privilegiado para la "identificación de buenas prácticas en el campo de los derechos humanos".

18. De manera similar, en su Resolución 334(2011) "Desarrollando indicadores para la sensibilización en derechos humanos a nivel local y regional", el Congreso recordó "el hecho de que los derechos humanos incluyen los derechos civiles, políticos, económicos y sociales, y que las competencias de las autoridades locales y regionales se extienden a todos estos derechos" y, en consecuencia, la pertinencia de garantizar que las actividades de entes territoriales "se basen en la jurisprudencia del Tribunal Europeo de Derechos

\footnotetext{
${ }^{9}$ Doc. 14462,5 de enero de 2018, p. 12.

${ }^{10}$ www.coe.int/fr/web/congress/youth.
} 
Humanos y de la Carta Social Europea, así como en el trabajo de los actuales órganos de supervisión del Consejo de Europa".

19. El Congreso adoptó esta metodología e insistió en dicha estrategia en su Resolución 365(2014), "Buenas prácticas para la efectividad de los derechos humanos a nivel local y regional en los estados miembros del Consejo de Europa", teniendo en cuenta el trabajo realizado por el Sector de la Juventud del Consejo de Europa a favor de la promoción de los derechos humanos, la inclusión social y la participación activa de los jóvenes (especialmente a través del proyecto "Enter!", implementado desde 2009) ${ }^{11}$.

20. Por otra parte, el Congreso se ha apoyado en otros instrumentos precedentes en el terreno de la integración, la participación y el compromiso de los jóvenes a nivel local y regional $^{12}$ incidiendo en el acceso a sus derechos sociales, al tiempo que tomando en consideración un enfoque integrado y basado en la indivisibilidad de todos los derechos humanos. En su informe "El voto a los 16 años - consecuencias sobre la participación juvenil a nivel local y regional" 13 , el Congreso, considerando las elecciones como la principal "correa de transmisión" de la participación política de los ciudadanos, insta a las autoridades a que promuevan la reducción de la edad para el sufragio a los 16 años en las elecciones locales y regionales.

21. En su Resolución 414(2017) ¿Eternamente joven? El papel de las políticas de juventud y del trabajo juvenil a nivel local y regional para apoyar la transición de los jóvenes hacia la autonomía y la vida profesional", el Congreso dirigió a las autoridades locales y regionales recomendaciones concretas sobre:

a. información (por ejemplo, establecer centros de información, asesoramiento y apoyo en línea y cara a cara, que ofrezcan a los jóvenes un acompañamiento individual y formaciones específicas),

b. educación (por ejemplo, favorecer el acceso al aprendizaje y suministrar asistencia para continuar una formación después de los 18 años),

c. empleo (por ejemplo, crear una cartera municipal para el reconocimiento de las competencias adquiridas a través de períodos de prácticas y actividades de voluntariado que deberían ser oficialmente homologadas y validadas como experiencia profesional),

\footnotetext{
${ }^{11} \mathrm{https}$ ///www.coe.int/fr/web/enter/cooperation-with-local-authorities.

${ }^{12}$ Entre otras, Resolución 386(2015) "Adoptar un lenguaje común entre la juventud y las entidades locales para eliminar las barreras a la participación juvenil"; Resolución 366(2014) "Empoderar a la juventud de etnia gitana a través de la participación: diseñar políticas efectivas a nivel local y regional"; Resolución 346(2012) "Juventud y democracia: la evolución del compromiso político de las y los jóvenes"; Resolución 319(2010), "La integración de la juventud de los barrios desfavorecidos"; Resolución 259(2008), "La integración y la participación de la juventud a nivel local y regional”.

${ }^{13}$ CG2015(29)final.

ISSN: $2174-6419$

Lex Social, vol. 10, núm. 1 (2020)
} 
d. vivienda (por ejemplo, desarrollar ofertas de vivienda asequible para jóvenes, con oportunidades de préstamos y apoyo financiero municipal),

e. salud (ofertar regularmente sesiones informativas y de formación sobre derechos sexuales y reproductivos, depresión, violencia, acoso u otros problemas relacionados con la salud).

22. Con la misma filosofía, en su Recomendación CM/Rec(2015)3 sobre el acceso de la juventud de los barrios desfavorecidos a los derechos sociales ${ }^{14}$, el Comité de Ministros aludió expresamente a un gran número de disposiciones de la Carta Social revisada de 1996 (artículos 1, 7, 9, 10, 11, 15, 17, 19, 21, 30 y 31), además de tener en cuenta las "conclusiones y decisiones pertinentes del CEDS". Esta recomendación enfatiza el acceso a ciertos derechos sociales (educación de calidad, empleo estable, condiciones de vida dignas, transporte adecuado, atención sanitaria, tecnologías y oportunidades de participación social, cultural y económica) como "condición previa para la integración y la ciudadanía activa de todos los jóvenes" y contiene un anexo muy detallado con medidas relativas al acceso de los jóvenes de los barrios desfavorecidos a los derechos sociales. La recomendación también sugiere medidas susceptibles de ser adoptadas por las autoridades locales y regionales.

23. Las propuestas de esta recomendación se retoman, con un alcance más general, en la Recomendación CM/Rec(2016)7 del Comité de Ministros a los Estados miembros sobre el acceso de la juventud a los derechos, la cual apela asimismo a las "decisiones y conclusiones del Comité Europeo de Derechos Sociales" e invita a los Estados que aún no lo hayan hecho a ratificar la Carta Social Europea revisada de 1996 y el Protocolo de 1995 que establece el procedimiento de reclamaciones colectivas. En el anexo de esta recomendación, el Comité de Ministros insta igualmente a los Estados miembros a "facilitar el acceso de los jóvenes a los derechos sociales fortaleciendo la aplicación de la Carta Social Europea".

24. En dicha recomendación, el Comité de Ministros retoma la Recomendación (ya citada) de la Asamblea Parlamentaria 2015(2013) sobre el acceso de los jóvenes a los derechos fundamentales, en donde la Asamblea se congratula por la puesta en marcha de la campaña "Haced crecer los derechos humanos", lanzada por el Consejo de Europa en febrero de 2013, "cuyo objetivo es promover los derechos y libertades consagrados en el Convenio Europeo de Derechos Humanos, poniendo el acento en los jóvenes. Considera que esta campaña debería ampliarse para incluir igualmente los derechos garantizados por la Carta Social Europea (revisada)".

\footnotetext{
${ }^{14}$ Véase asimismo O’Kelly, Kevin y Muir, John: A prendre au sérieux. Guide de la Recommandation CM/Rec(2015)3 du Comité des Ministres du Conseil de l'Europe aux États membres sur l'accès des jeunes des quartiers défavorisés aux droits sociaux (Éd. Mara Georgescu et Rui Gomes), Strasbourg, éditions du Conseil de l'Europe, $2016, \quad 74 \quad$ páginas (https://rm.coe.int/CoERMPublicCommonSearchServices/DisplayDCTMContent?documentId=09000016 806ce531).
} 


\subsection{La naturaleza subsidiaria del Convenio Europeo de Derechos Humanos}

25. El CEDH no reconoce explícitamente los derechos y libertades relacionados con los jóvenes. Es cierto que la jurisprudencia del Tribunal Europeo de Derechos Humanos muestra casos presentados por jóvenes demandantes en los que estaba en juego la protección de ciertos derechos (en particular civiles y políticos e, indirectamente, sociales). Pero dicha jurisprudencia tiene un alcance muy limitado en comparación con la jurisprudencia que emana de la Carta Social, que tiene un alcance personal y material más amplio. Debido a ello, resulta muy difícil extraer de la jurisprudencia del Tribunal ejemplos de buenas (o malas) prácticas relacionadas con el acceso a los derechos sociales por parte de los jóvenes que puedan tenerse en cuenta a nivel local y regional ${ }^{15}$.

26. Pese a ello, la fundamental posición del CEDH como tratado "emblemático" del Consejo de Europa y las campañas de sensibilización (con respecto a los derechos reconocidos) dirigidas a los jóvenes también pueden resultar útiles con respecto a la Carta Social y los derechos sociales más vinculados a la juventud: por ejemplo, el proyecto "¡Date prisa! ¡Derechos humanos revisitados por la juventud en Europa!" ("Hurry Up! Human Rights Revisited by Youth in Europe!"), lanzado con motivo de la celebración del $60^{\circ}$ aniversario del CEDH (se realizaron diferentes actividades durante los diez meses del proyecto, de septiembre de 2010 a junio de 2011).

27. Esta iniciativa de la ciudad de Estrasburgo, apoyada por el programa europeo "Juventud en acción" y llevada a cabo en colaboración con el Tribunal Europeo, reunió a numerosas ciudades y organizaciones: Dresde (Alemania), ciudad hermanada con Estrasburgo, y siete ciudades integrantes del Club de Estrasburgo: Budapest (Hungría), Timisoara (Rumania), Katowice (Polonia), Riga (Letonia) Stara Zagora y Ruse (Bulgaria), Kutaisi (Georgia). Además, en la estela del Año Europeo del Voluntariado, "Hurry Up" tenía como objetivo alentar a los jóvenes a comprometerse mediante la

\footnotetext{
15 Véase, por ejemplo, la recopilación del Tribunal Europeo (únicamente en inglés) sobre jóvenes de entre 18 y 35 años publicado por la División de Investigación del Tribunal en 2012: Research Report. Selected case-law of the European Court of Human Rights on young people, Conseil de l'Europe/Cour européenne des Droits de 1'Homme, 2012, 26 páginas (www.echr.coe.int, Case-law - Case-law Analysis - Research Reports). En particular, esta selección nos presenta algunas decenas de sentencias del Tribunal (o incluso decisiones o informes de la antigua Comisión Europea de Derechos Humanos) sobre objeción de conciencia al servicio militar, expulsión de jóvenes migrantes de segunda generación y trabajo forzado (los derechos de personas extranjeras están en juego en muchos de estos casos), así como un asunto relacionado con el acceso a la carrera profesional (bajo el ángulo de la vida familiar, pues la homologación de diplomas universitarios topa con obstáculos "ratione materiae" o caen dentro del margen de apreciación del Estado referente al ejercicio de una profesión) y dos casos cuyos litigios se originaron en el ámbito universitario (en relación con el idioma de enseñanza para ciertas clases o con el uso de símbolos religiosos). La jurisprudencia posterior del Tribunal proporciona ejemplos interesantes, entre otros, de jóvenes migrantes que son víctimas de trabajo forzoso (caso Chowdury y otros c. Grecia, de 30 de marzo de 2017, violación del artículo 4\$2) o de jóvenes con discapacidad que se enfrentan a barreras físicas para acceder a los centros universitarios (caso Enver Şahin c. Turquía, de 30 de enero de 2018, violación del artículo 14 -no discriminación- combinado con el artículo 2 del Protocolo $n^{\circ} 1$-educación-), etc.; ahora bien, el alcance de esta jurisprudencia es aún modesto con respecto a la implementación de los derechos sociales de las y los jóvenes a nivel local y regional.
} 
creación de una red juvenil de embajadores de los derechos humanos y la democracia en Europa.

\subsection{La naturaleza complementaria de las acciones de la Unión Europea (UE)}

28. El derecho primario de la UE, en particular el Tratado de Funcionamiento de la UE (TFUE), aborda la problemática social de la juventud, especialmente bajo el ángulo del mercado laboral y del "intercambio de trabajadores jóvenes" (artículo 47). Del mismo modo, con el fin de desarrollar la dimensión europea en los ámbitos de la educación, la formación profesional y el deporte, la acción de la Unión tiene como objetivo "favorecer el incremento de los intercambios de jóvenes y de animadores socioeducativos, y fomentar la participación de los jóvenes en la vida democrática de Europa"(artículo 165), así como "facilitar el acceso a la formación profesional y favorecer la movilidad de los educadores y de las personas en formación, especialmente de los jóvenes" (artículo 166). Adicionalmente, en el terreno de la acción exterior de la Unión, "a fin de establecer un marco para que los jóvenes europeos puedan aportar contribuciones comunes a las acciones de ayuda humanitaria de la Unión, se creará un Cuerpo Voluntario Europeo de Ayuda Humanitaria" (artículo 214) ${ }^{16}$.

29. En lo que respecta al acceso de los jóvenes a los derechos sociales en los instrumentos de derecho programático o no vinculante, el preámbulo del "Pilar europeo de derechos sociales"17 subraya la necesidad de abordar la inseguridad económica y social para "ofrecer mejores oportunidades a la juventud" en "una Unión en la que los jóvenes reciban la mejor educación y formación, y puedan estudiar y encontrar trabajo en todo el continente" (párrafo 7), ya que "las consecuencias sociales de la crisis han tenido un gran alcance, desde el desempleo juvenil y a largo plazo hasta el riesgo de pobreza, y hacer frente a estas consecuencias sigue siendo una prioridad urgente" (párrafos 9-10). Para hacer frente a estas consecuencias, el Capítulo I del Pilar ("Igualdad de oportunidades y de acceso al mercado de trabajo") destaca el "apoyo activo para el empleo" y proclama que "los jóvenes tienen derecho a educación continua, una formación como aprendices, un período de prácticas o una oferta de empleo de buena calidad en los cuatro meses siguientes a quedar desempleados o finalizar los estudios"(párrafo 4.b).

16 En el marco de la UE, también cabe mencionar el "Cuerpo Europeo de Solidaridad" (https://europa.eu/youth/solidarity_es), que tiene como objetivo dar a las y los jóvenes la oportunidad de ser voluntarios o trabajar en la UE en el marco de proyectos organizados en su país o en el extranjero y destinados a ayudar a comunidades y a personas en toda Europa. En el marco del Consejo de Europa, debe hacerse referencia al Convenio europeo sobre la promoción de un servicio voluntario transnacional a largo plazo para la juventud (adoptado el 11 de mayo de 2000). Por su parte, en la Resolución 346(2012) "Juventud y democracia: la evolución del compromiso político de las y los jóvenes", el Congreso recomendó la adopción de "políticas locales sobre la actividad de voluntariado, velando, no obstante, por que este tipo de actividad no sea un sustituto del empleo remunerado, para propiciar que las y los jóvenes adquieran habilidades personales y profesionales".

17 https://ec.europa.eu/commission/priorities/deeper-and-fairer-economic-and-monetary-union/europeanpillar-socialrights_en. Véase la Proclamación interinstitucional sobre el pilar europeo de derechos sociales por el Parlamento Europeo, el Consejo y la Comisión (DO C 428 de 13 de diciembre de 2017, p. 9).

ISSN: $2174-6419$

Lex Social, vol. 10, núm. 1 (2020) 
30. En realidad, este capítulo del Pilar recuerda las grandes líneas de la Recomendación del Consejo Europeo de 22 de abril de 2013 sobre el establecimiento de una garantía para la juventud: esta insta a los Estados miembros a que garanticen que a todos los jóvenes menores de 25 años se les ofrezca un empleo de calidad, una formación continua, un período de aprendizaje o una pasantía dentro de los cuatro meses posteriores a la pérdida de su trabajo o al final de la educación formal. El principal desafío consiste en garantizar una implementación completa y sostenible de la Garantía Juvenil extendiendo su aplicación a todos los jóvenes ${ }^{18}$.

31. Al margen de las ya aludidas disposiciones generales del Derecho primario y del Derecho programático (el Pilar) de la UE relativas a los jóvenes, debe mencionarse la Estrategia para la Juventud acordada por los Ministros de la UE. La estrategia hasta ahora vigente definía un marco de cooperación para el período $2010-2018^{19}$ proponiendo iniciativas en ocho áreas: empleo y emprendimiento, inclusión social, participación en la sociedad civil, educación y formación, salud y bienestar, actividades de voluntariado, los jóvenes y el mundo, creatividad y cultura.

32. La Estrategia Europea para la Juventud cuenta asimismo con el apoyo de otras iniciativas complementarias, tales como el Programa "Erasmus $+{ }^{+20}$. Se presenta una vasta panoplia de acciones concretas en cada guía anual del Programa. Las acciones de sensibilización previstas para $2018^{21}$ ya han sido practicadas en años anteriores: por ejemplo, una campaña europea de información sobre el acceso a los derechos sociales para los jóvenes "Inclusion Express" en 2015, con acciones locales a favor del acceso a los derechos sociales para jóvenes migrantes, refugiados y solicitantes de asilo $^{22}$.

\section{PROBLEMAS Y BUENAS PRÁCTICAS RELACIONADAS CON EL ACCESO JUVENIL A LOS DERECHOS SOCIALES A NIVEL LOCAL Y REGIONAL}

\subsection{Derechos sociales de la juventud y aspectos multifactoriales}

33. El tamaño, así como la organización constitucional del país (más o menos descentralizada territorialmente), son susceptibles de ejercer una influencia significativa en las prácticas y la financiación de las acciones específicas dirigidas a los jóvenes.

\footnotetext{
${ }^{18}$ Véase la Comunicación de la Comisión de octubre de 2016 titulada "La Garantía Juvenil y la Iniciativa de Empleo Juvenil, tres años después" [COM(2016) 646 final]; y su Comunicación de diciembre de 2016 titulada "Invertir en la juventud de Europa" [COM (2016)940 final].

${ }^{19}$ En mayo de 2018, la Comisión Europea presentó propuestas para una nueva Estrategia de la UE para la Juventud para el período 2019-2027 (https://ec.europa.eu/youth/sites/youth/files/ youth_com_269_1_en_act_part1_v9.pdf, visitado el 5 de septiembre de 2018).

${ }^{20}$ Reglamento (UE) n ${ }^{\circ} 1288 / 2013$ del Parlamento Europeo y del Consejo, de 11 de diciembre de 2013, por el que se establece "Erasmus +": el Programa de la Unión para la Educación, la Formación, la Juventud y el Deporte (http://eurlex.europa.eu/LexUriServ/LexUriServ.do?uri=OJ:L:2013:347:0050:0073:ES:PDF).

${ }^{21}$ Comisión Europea: Eramus + Guía del Programa 2018, p. 76.

${ }^{22}$ Nombre del titular del proyecto: "Réseau Express Jeunes". Más información sobre este proyecto y otros, en Agencia del servicio cívico: Informe de actividad 2016, p. 22 (https://www.servicecivique.gouv.fr/uploads/resource_block/fb7654839e1d0c732f715b1d7b7b3093caee4bf6.pdf). 
34. En Francia, se ha revelado necesario lanzar grandes programas para promover la inclusión social de los jóvenes con autismo ${ }^{23}$. Datos recientes en Francia han puesto de manifiesto que el $90 \%$ de los jóvenes autistas en edades comprendidas entre los 16 y los 19 años no contaban con ninguna oportunidad de continuar escolarizados. Ahora bien, la misión fundamental de la institución escolar podría cumplirse mejor en el caso de niños y adolescentes con autismo si pudieran continuar efectivamente su escolaridad más allá de los 16 años, edad de escolarización obligatoria en Francia. Por tal razón, la CEDS consideró que la exclusión, en la práctica, de los niños y adolescentes autistas del derecho a proseguir su vida escolar más allá del límite de edad de la educación obligatoria, un derecho sin embargo reconocido por ley a todo alumno, equivalía a una falta de oportunidades para las personas interesadas en desarrollar sus capacidades en el entorno escolar ordinario ${ }^{24}$.

35. Diversamente, el tamaño de Andorra (con un pequeño número de casos de jóvenes con autismo) ha permitido poner en práctica programas como "Jóvenes en inclusión" ("Joves en inclusió") con el fin de incluir en la comunidad a las personas que padezcan trastornos del espectro autista. Se lleva a cabo desde 2017 como una experiencia piloto por parte de una entidad privada ("Fundación Privada Tutelar del Principado de Andorra", "Fundació Privada Tutelar del Principat d'Andorra") con la colaboración del Gobierno de Andorra y de la entidad local interesada (Escaldes-Engordany) ${ }^{25}$.

36. Por lo demás, no cabe descartar la cooperación internacional en este ámbito. Por ejemplo, en el marco de la cooperación entre el Ministerio de Trabajo y Protección Social de Azerbaiyán y la Agencia Turca de Cooperación y Coordinación (TIKA), se organizó en 2015 un curso de formación profesional "Arıc1" (" Apicultores") para doce demandantes de empleo con discapacidad que viven en la ciudad de Shamakhi ${ }^{26}$. Por añadidura, con el apoyo de la TIKA, una veintena de jóvenes participaron en el curso

\footnotetext{
${ }^{23}$ Especialmente, los planes de acción sucesivos que cubren los períodos 2005-2007 (primer plan de autismo), 2008-2010 (segundo plan de autismo), 2013-2017 (tercer plan de autismo) y 2018-2022 (cuarto plan de autismo: http: // comprendrelautisme.com/quatriemeplan-autisme-2018-2022/). El contenido de estos Planes de Autismo se ha visto influido en gran medida por la acción del Consejo de Europa: véanse las decisiones del CEDS de 4 de noviembre de 2003 (Reclamación № 13/2002, Asociación Internacional Autismo-Europa c. Francia) y de 11 de septiembre de 2013 (Reclamación No 81/2012, Acción Europea de las Personas con Discapacidad c. Francia).

${ }^{24}$ Decisión del CEDS de 11 de septiembre de 2013 (Reclamación № 81/2012, Acción Europea de las Personas con Discapacidad c. Francia), párrafos 92-93.

${ }^{25}$ El programa, iniciado con cinco jóvenes autistas de entre 16 y 25 años en la parroquia de EscaldesEngordany, funciona por objetivos (evaluación continua) de manera integral en todas las áreas de la vida cotidiana para apoyar su transición hacia la autonomía y la vida profesional: cuídate (hacer compras, tomar un taxi), ocio (ir al cine), empleo. $11^{\circ}$ informe de Andorra sobre el cumplimiento de la CSE, 22 de noviembre de 2017, RAP/RCha/AND/11(2018), p. 70: https://rm.coe.int/11e-report-of-theandorre/168077630d].

$2611^{\circ}$ informe de Azerbaiyán sobre el cumplimiento de la CSE, 3 de abril de 2018, RAP/RCha/AZE/11(2018), p. 42 (https://rm.coe.int/11th-report-from-azerbaijan/16807b6c7d). 
"Diseño de mosaicos" en el Centro de Readaptación Profesional para Jóvenes con Discapacidad de Ramana en $2016^{27}$.

37. De igual manera, el entorno (urbano o rural) puede condicionar las medidas de sensibilización de la juventud en materia de derechos sociales. Así, puede observarse la diferencia entre una campaña que busca disuadir a los jóvenes de asumir riesgos (para su vida y su salud) a causa de la triste práctica del balconing (por ejemplo, en las Islas Baleares en España ${ }^{28}$ ) y una campaña orientada a proteger la salud de los jóvenes en las familias de agricultores (por ejemplo, la campaña ¡Fit4life - implícate!, Fit4life - get involved!, Fit4life - sei dabei!, en Austria) ${ }^{29}$.

\subsection{Buenas prácticas "convencionales" para la promoción de ciertos derechos sociales (salud) adaptándose a las fórmulas "modernas" de acceso juvenil}

38. Como es sabido, la lucha contra el tabaquismo, el alcoholismo y la toxicomanía o abuso de drogas es tradicionalmente objeto de campañas de prevención en todos los países y en todos los niveles territoriales. Aunque esta problemática afecte al conjunto de la población, es evidente que las necesidades de información y disuasión son más acentuadas entre los jóvenes. Desde este punto de vista, los compromisos de los Estados en virtud del artículo 11 de la Carta Social (salud), así como la jurisprudencia del CEDS en este ámbito ${ }^{30}$, muestran ejemplos de buenas prácticas. Detengámonos en algunos de ellos.

\footnotetext{
${ }^{27}$ Ibidem.

${ }^{28}$ Esta práctica (consistente en saltar desde el balcón del hotel para intentar sumergirse en la piscina o alcanzar otro balcón) ha provocado accidentes muy graves que han afectado especialmente a jóvenes turistas. Véase Segura Sampedro, Juan José y otros: " Balconing: An alcohol-induced craze that injures tourists. Characterization of the phenomenon", Injury, 48 (7), julio de 2017, pp. 1371-1375: Se trata de un estudio retrospectivo de cinco años (entre 2010 y 2015) que se realizó en las Islas Baleares (46 casos). En 44 casos $(95,65 \%)$, el consumo de alcohol estuvo presente, acompañado de otras drogas en 17 casos (36,96\%). La conclusión: el balconing casi siempre está relacionado con el consumo excesivo de alcohol u otras drogas. Descripción de buenas prácticas implementadas en 2018 para tratar de contrarrestar el problema: campañas de concientización (con videos) en Gran Bretaña y en colaboración con la Embajada del Reino Unido en España; campañas de sensibilización por parte de las autoridades locales (el municipio de Calvià o la ciudad de Palma de Mallorca) en colaboración con hoteleros (distribución de folletos para advertir a las personas, etc.), o nuevas normas e instrucciones que intensifican la imposición de multas por la práctica del balconing y el consumo de alcohol en espacios públicos.

${ }^{29}$ La campaña "Fit 4life - sei dabei" fue lanzada en 2011 por la Caja de Seguridad Social para Agricultores (Sozialversicherungsanstalt der Bauern, $S V B$ ). Con base en estudios sobre la situación de niños y jóvenes de familias de agricultores, los objetivos específicos de la campaña en 2016 consistieron en reducir el número de accidentes por caídas a través de medidas estructurales y técnicas, para minimizar las consecuencias de tales accidentes, así como para ayudar a las personas de grupos específicos a mejorar su equilibrio y coordinación: $5^{\circ}$ informe de Austria sobre el cumplimiento de la CSE, 4 de noviembre de 2016, RAP/RCha/AUS/5(2017), p. 31-32

(https://rm.coe.int/CoERMPublicCommonSearchServices/DisplayDCTMContent?documentId=09000016 $806 \mathrm{c} 2 \mathrm{fad})$.

${ }^{30}$ Digesto de Jurisprudencia del Comité Europeo de Derechos Sociales, 1 de septiembre de 2008, p. 87, https://rm.coe.int/CoERMPublicCommonSearchServices/DisplayDCTMContent?documentId=09000016 $804915 \mathrm{a} 0$.
} 
39. Las medidas preventivas contra el tabaquismo en Austria han consistido, entre otros aspectos, en el establecimiento de una línea de servicio de información para fumadores, un número de asistencia telefónica para las personas que desean dejar de fumar, o la campaña YOLO "Vive tu vida. No fumes ". "Live your life. No smoking, YOLO" "YOLO" (You only Live Once/Solo se vive una vez) fue el eslogan de la campaña lanzada por el Ministerio Federal de Salud dirigidas a jóvenes adolescentes con motivo del Día Mundial Sin Tabaco, el 31 de mayo de 2015. Los jóvenes utilizan este eslogan para animarse mutuamente a aprovechar la oportunidad de abstenerse de fumar. "YOLO" expresa la esencia de la actitud de los jóvenes hacia la vida, es decir, vivir aquí y ahora. La información se presenta en línea en www.yolo.at, Facebook y WhatsApp ${ }^{31}$.

40. En Italia, como parte de la promoción de estilos de vida saludables, el Ministerio de Salud, en los últimos años, ha llevado a cabo una intensa actividad de información y sensibilización destinada a combatir el abuso de alcohol, especialmente entre los jóvenes. Por ejemplo, la campaña "La vita è sempre una anche se hai bevuto" ("Solo hay una vida, incluso cuando has bebido") utilizó diferentes herramientas y medios de comunicación y se lanzó durante el verano de $2012^{32}$. En 2015, se implementó la iniciativa "Alcol Snaturato - Una serata speciale" ("Alcohol desnaturalizado - Una velada especial"). "Alcol Snaturato" es el título de la canción que el Ministerio de Salud produjo en colaboración con un famoso grupo musical nacional. El objetivo de la campaña era llamar la atención sobre el comportamiento de los jóvenes que abusan del alcohol y corregir el déficit de percepción alimentado por los medios de comunicación, que en la juventud describen el alcohol como un facilitador del éxito ${ }^{33}$.

41. De todas formas, dejando de lado estos tres problemas clásicos (tabaco, alcohol, drogas), el derecho al más alto nivel posible de salud debe comprender el bienestar físico y mental de acuerdo con la definición de salud de la Organización Mundial de la Salud. Desde esta óptica, también se trata de animar a los jóvenes a desarrollar un sentido de responsabilidad individual en áreas como la alimentación, la sexualidad o el medio

\footnotetext{
$315^{\text {o }}$ informe de Austria sobre el cumplimiento de la CSE, 4 de noviembre de 2016, RAP/RCha/AUS/5(2017), p. 72-73: https://rm.coe.int/CoERMPublicCommonSearchServices/DisplayDCTMContent?documentId=09000016 $806 \mathrm{c} 2 \mathrm{fad}$.

${ }^{32}$ En primer lugar, se utilizaron todos los periódicos nacionales más leídos en la prensa diaria y periódica y en la prensa en línea. Luego, se emitió un spot de radio en los circuitos de las emisoras comerciales más escuchadas a nivel nacional y local. Además, para promover la penetración del mensaje entre las y los jóvenes, se produjo una colaboración activa del portal Studenti.it, que propició más de 100.000 contactos específicos. Y siempre en el sector juvenil, también se desarrolló una aplicación para teléfonos móviles con contenido informativo y recreativo, desarrollada en colaboración con la compañía Sony, que obtuvo, en solo 20 días, 14.000 descargas y 220.146 impresiones. Con respecto a los eventos relacionados con la campaña, el Ministerio de Salud financió asimismo la organización de diferentes ediciones del Día de Prevención del Alcohol. $16^{\circ}$ informe de Italia sobre el cumplimiento de la CSE, 7 de marzo de 2017, RAP/RCha/ ITA / 16 (2017), p. 40-41: https://rm.coe.int/16806fe976].

${ }^{33}$ Ibidem.
} 
ambiente. Una iniciativa interesante que afecta a la juventud universitaria es la Red Española de Universidades Saludables ${ }^{34}$.

\subsection{Buenas prácticas "más generales" centradas en el acceso de la juventud a los derechos sociales}

42. En este caso vale la pena traer a colación una ilustración de buenas prácticas "multidimensional" e "integrada" (lanzada por la Presidenta a la sazón del Parlamento regional de Canarias): la exposición "La Carta Social Europea: nuestros derechos" organizada por las autoridades autonómicas (ejecutiva y legislativa) en Santa Cruz de Tenerife en abril-mayo de 2017 con la colaboración de las Escuelas Superiores de Arte y Diseño de Tenerife, siendo los estudiantes (los propios jóvenes) los artistas (protagonistas) de las obras expuestas (diseño de marquesinas de autobuses con el logotipo de la Carta Social, fotos, esculturas, etc., con mensajes e imágenes que buscan "hacer entrar por los ojos" todos los derechos reconocidos por la Carta Social).

43. Esta iniciativa estuvo acompañada por la declaración del 18 de octubre como "Día de la Carta Social Europea", en Bruselas, en junio de 2017, en la Conferencia de las Asambleas Legislativas Regionales Europeas (CALRE), a propuesta de la Presidenta del Parlamento regional de Canarias. Además del 18 de octubre, sería pertinente organizar actividades de promoción de los derechos sociales de la juventud en otras fechas importantes, tales como el Día Internacional de la Juventud promovido por la UNESCO cada año el 12 de agosto.

\subsection{Medios modernos de acceso a los derechos sociales y heterogeneidad de la juventud en términos de educación}

44. Según la UNESCO, la "juventud" constituye un grupo heterogéneo en constante evolución. En este sentido, incluso si tiene en cuenta la definición utilizada por las Naciones Unidas de que el término "juventud" abarca un grupo de edad de entre los $15 \mathrm{y}$ los 25 años, la Organización universal considera que la experiencia de "ser joven" varía enormemente de un país a otro y, por lo tanto, dicha definición sigue siendo flexible y varía en función del contexto.

45. Dicho esto, es verdad que el uso de plataformas en línea favorece el acceso de los jóvenes a los derechos sociales, ya que permiten establecer redes de jóvenes comprometidos política y socialmente, así como compartir conocimientos. Los medios de comunicación, las redes sociales, los blogs, etc., pueden dar voz a los jóvenes y abrir canales de reacción o respuesta directa a los responsables gubernamentales en todos los

$3429^{\circ}$ informe de España sobre el cumplimiento de la CSE, 19 de octubre de 2016, RAP/RCha/ESP/29(2017), $\quad$ p. $3:$ https://rm.coe.int/CoERMPublicCommonSearchServices/DisplayDCTMContent?documentId=09000016 $806 \mathrm{c} 2 \mathrm{fc} 2$. 
niveles. Desde este punto de vista, el desafío de la buena gobernanza (abierta y transparente) y la democracia en línea no debe descuidar el desafío previo de la educación para poder utilizar los nuevos centros de tecnología informática (las TICs) puestos a disposición por las autoridades locales y regionales ${ }^{35}$.

46. En efecto, la juventud no debería ser percibida como una entidad homogénea. Por ejemplo, se ha vuelto común hablar de jóvenes nacidos en la era de la información como "nativos digitales". Pero la brecha de alfabetización entre las áreas urbanas y rurales sigue siendo notable ${ }^{36}$, razón por la cual los jóvenes afectados por desventajas económicas o sociales tienden a tener habilidades digitales más débiles ${ }^{37}$. Para hacer frente a semejante desafío, la Comisión Europea adoptó en enero de 2018 un plan de acción en materia de educación digital ${ }^{38}$.

\subsection{Acceso de la juventud a la educación}

47. En la actualidad, el acceso de la juventud a la educación se enfrenta al menos a dos desafíos principales: de un lado, se trata de ayudar a los jóvenes a completar la educación secundaria superior con el fin de reducir la tasa de abandono escolar; de otro lado, se trata asimismo de ayudar a los jóvenes a seguir estudios universitarios con becas o con préstamos razonablemente reembolsables. Desafortunadamente, en algunos países, la crisis económica ha provocado un aumento de las tasas universitarias y la sustitución de becas por préstamos contratados directamente por los estudiantes a tasas de interés irrazonables $^{39}$, y todo ello como medida para reducir el gasto público y el déficit. Como consecuencia de ello, existe un problema real de endeudamiento estudiantil en Europa y en todo el mundo a escala global ${ }^{40}$.

48. En este panorama, el artículo 10 de la Carta Social de 1961 (revisada en 1996), a la luz de la interpretación del CEDS, comprende el derecho a la educación superior con un alcance muy amplio (por ejemplo, el derecho de acceso a la educación o el derecho a una asistencia financiera). Sin embargo, la preocupación por la seguridad jurídica condujo a los representantes de la juventud (y en particular a la Asociación de Estados Generales de

\footnotetext{
${ }^{35}$ Recordemos la célebre frase de Jean Jacques Rousseau (Du contrat social, 1762 Livre, I): "Cualquier influencia, por débil que sea, que pueda tener mi voz en los asuntos públicos, hace que la existencia del derecho al voto sea suficiente para imponerme el deber de instruirme".

${ }^{36}$ Mejorar la participación política de la juventud a lo largo del ciclo electoral. Guía de buenas prácticas, Programa de las Naciones Unidas para el Desarrollo, Nueva York, 2013, p. 13 (http://www.undp.org/content/dam/undp/library/Democratic\%20Governance/Electoral\%20Systems\%20a nd\%20Processe s / FR_UN-Youth_Guide-LR.pdf).

${ }^{37}$ Comisión Europea: The International Computer and Information Literacy Study (ICILS): Main findings and implications for education policies in Europe, 2014, http://ec.europa.eu/dgs/education_culture/repository/education/library/study/2014/ ec-icils_en.pdf.

${ }^{38}$ Documento de trabajo de los servicios de la Comisión sobre el Plan de acción para la educación digital, COM (2018) 22 final, Bruselas, 17.1.2018 SWD(2018) 12 final, p. 10.

39 OCDE: Education at a Glance 2017: OECD Indicators, OECD Publishing, Paris 2017 (https://www.hm.ee/sites/default/files/eag2017_eng.pdf).

40 Toca, Gonzalo: "Universitarios endeudados: una polémica global", esglobal, 28 de agosto de 2018 (https://www.esglobal.org/universitarios-endeudados-una-polemica-global/). 
Estudiantes de Europa, AEGEE-Europe/European Students' Forum) a formular en abril de 2002 una propuesta para enmendar la Carta Social reforzando el ámbito aplicativo del artículo 10 mediante el reconocimiento autónomo del derecho a la educación superior ${ }^{41}$.

\subsection{Acceso de la juventud al mercado laboral}

\subsubsection{Crisis económica y precarización laboral de la juventud}

49. El Consejo de Europa, y señaladamente el CEDS, se ha visto confrontado a medidas restrictivas de los derechos sociales fundamentales reconocidos por la Carta Social en el período más delicado de la crisis económica, en particular con motivo del examen de algunos casos griegos. Más específicamente, las primeras dos decisiones que abordaron directamente la cuestión de las medidas de austeridad y de flexibilidad del mercado laboral (adoptadas bajo la influencia de la Troika) y que afectan especialmente a la juventud, fueron tomadas por el CEDS el 23 de mayo de 2012.

50. En la primera decisión (Reclamación n 65/2011, GENOP-DEI y ADEDY c. Grecia), el CEDS concluyó que había habido una violación del artículo $4 \S 4$ de la Carta Social, en la medida en que ley nacional autorizaba el despido sin preaviso ni indemnización de los empleados con un contrato de duración indefinida durante los primeros doce meses.

51. En la segunda decisión (Reclamación nº 66/2011, GENOP-DEI y ADEDY c. Grecia), el CEDS concluyó que había habido una violación de varias disposiciones de la Carta Social (artículos 7§7, $10 \S 2,12 \S 3$ y 4\$1), tras haber examinado las disposiciones restrictivas sobre vacaciones anuales, sistemas de aprendizaje y capacitación para niños y niñas, y la cobertura de la seguridad social en los llamados "contratos especiales de aprendizaje" estipulados entre empleadores y jóvenes entre edades comprendidas entre los 15 y 18 años, así como las disposiciones relativas a la remuneración irrisoria (un pequeño porcentaje del salario mínimo nacional) susceptible de ser percibida por los empleados menores de 25 años, "la cual está por debajo del umbral de pobreza" (párrafo 65) y es claramente discriminatoria por motivo de edad (párrafos 68-70).

52. Por lo demás, vale la pena mencionar otra decisión en relación con los artículos $4 \S 1$ y $7 \S 5$ de la Carta Social (derecho a una remuneración justa, derecho de los niños y jóvenes a la protección). Se trata de la Reclamación (No. 150/2017) presentada por el Foro Europeo de la Juventud contra Bélgica, en la que se pide al Comité que determine que la práctica de pasantías no remuneradas contravendría esos artículos. El CEDS declaró admisible la denuncia el 5 de diciembre de 2017.

\footnotetext{
${ }^{41}$ Esta propuesta fue retomada por el Comité gubernamental de la Carta Social, pero finalmente no tuvo éxito: Propuesta de un Protocolo Adicional a la Carta Social Europea Revisada sobre el Derecho a la Educación Superior, Comité Gubernamental de la Carta Social Europea, Estrasburgo, 30 de julio de 2003 [TS-SG(2003)24].
} 


\subsubsection{Evitar que la crisis económica se convierta en una crisis de valores en la juventud}

53. La crisis económica de la última década ha provocado una precarización de la juventud no solo económica y socialmente (en términos de falta de oportunidades laborales), sino también política y culturalmente (en cuanto a su influencia en el campo profesional). En particular, estamos acostumbrados a examinar la problemática de la participación democrática de los jóvenes (incluida la edad para el ejercicio del derecho de sufragio), pero la preocupación por el grado de apatía de los jóvenes en la vida política debería ir acompañada de medidas para combatir la apatía de los trabajadores jóvenes en el mundo del trabajo (por ejemplo, el bajo porcentaje de afiliación sindical o de negociación de convenios colectivos $)^{42}$.

54. Esta apatía respecto de las "relaciones laborales" es la expresión de una crisis de valores paralela a la crisis económica. Ahora bien, las crisis económicas son cíclicas y pueden verse sucedidas de períodos de recuperación económica, mientras que las crisis de valores pueden conducir a una generación perdida y difícilmente recuperable. Esta apatía hace que sea muy complicada una eventual contestación por parte de la juventud frente a ciertas medidas tendentes a combatir el desempleo (flexiseguridad, formación, etc.). Por lo tanto, sería pertinente ampliar el alcance de las buenas prácticas de participación juvenil en la vida política transponiéndolas a la vida social ${ }^{43}$ : por ejemplo, la promoción de la actividad sindical y de la negociación colectiva según el espíritu de los artículos 5 y 6 de la Carta Social.

55. Dicha promoción está en consonancia con el espíritu de la nueva Estrategia operacional para la juventud (2014-2021) de la UNESCO ${ }^{44}$. La Estrategia se articula, entre otros vectores, en torno a procesos que permiten a los jóvenes de ambos sexos hacer valer sus derechos, asumir sus responsabilidades como ciudadanos activos y participar en la vida comunitaria: comprometiéndose con el voluntariado, como miembro de una organización juvenil, como impulsor de proyectos sociales, como pionero en innovación o creador de empresa ${ }^{45}$, colaborando con los medios de comunicación de la juventud y participando en los procesos de toma de decisiones.

\footnotetext{
42 15 informe de Estonia sobre el cumplimiento de la CSE, 3 de enero de 2018, RAP/RCha/EST/ 15(2018), p. 39-41: https://rm.coe.int/15th-national-report-from-estonia/1680779ff7]: "En Estonia y otros países, la afiliación sindical es más frecuente entre los trabajadores de más edad, lo que significa que cuando estos empleados alcanzan la edad de jubilación, ello tiene un impacto negativo significativo en la negociación colectiva, a menos que sean reemplazados por nuevas generaciones de empleados jóvenes. Según el estudio sobre la vida profesional, los jóvenes asalariados de Estonia no afilian a los sindicatos: solo el $2 \%$ de los jóvenes de entre 15 y 29 años pertenecían a sindicatos en 2015; (...)".

${ }^{43}$ Véase el Documento de trabajo de los servicios de la Comisión sobre el establecimiento de un pilar europeo de derechos sociales, Bruselas, 26 de abril de 2017, SWD (2017) 201 final, p. 37-38.

${ }^{44} \mathrm{http}$ ///unesdoc.unesco.org/images/0022/002271/227150e.pdf.

${ }^{45}$ Ficha del país - España y la Carta Social Europea, p. 7 (https://rm.coe.int/l-spain-and-the-EuropeanSocial-Charter/1680492a5d): Reducciones de las cotizaciones empresariales en el marco de medidas de apoyo al emprendedor y de estímulo del crecimiento y de la creación de empleo juvenil (Ley 11/2013, de 26 de julio de 2013).
} 


\subsubsection{Buenas prácticas y colaboración de los entes territoriales}

56. Aunque la implementación de la política de empleo dependa generalmente del nivel estatal, la colaboración de las entidades locales y regionales es muy importante en este ámbito. En efecto, las modalidades operativas de implementación local de las estrategias lanzadas a nivel nacional dan lugar a dinámicas de partenariado local que propician una optimización de los recursos de los territorios.

57. Por ejemplo, en la última década, Islandia ha combinado progresivamente proyectos nacionales con programas de colaboración con las autoridades locales ${ }^{46}$ :

a. A nivel estatal, cabe mencionar el proyecto "Juventud en acción" (Ungt fólk til athafna), que tenía como objetivo minimizar los efectos del desempleo de larga duración entre los jóvenes. Este proyecto ha estado en funcionamiento desde principios de $2010 \mathrm{y}$ va dirigido a personas de edades comprendidas entre los 16 y 29 años que están desempleadas e inscritas como beneficiarias de subsidios de desempleo, con la finalidad principal de mantener su actividad durante tres años después de la pérdida del empleo. El proyecto del gobierno se centró en las medidas de activación a través de la educación, la formación profesional y el trabajo voluntario.

\section{b. Colaboración formal con las autoridades territoriales - Programa "Job-square"} (Atvinnutorg). A principios de 2012, las autoridades locales de Reykjavík, Hafnarfjörður, Kópavogur y de la región de Suðurnes establecieron este programa para responder a las necesidades de los menores de 25 años de esas zonas que no estaban involucrados en programas de estudios ni insertados en el mercado laboral. Se trató de un proyecto conjunto que asoció a la Dirección de Trabajo, al Ministerio de Protección Social y a las corporaciones locales de las zonas concernidas. El objetivo radicaba en hacer más activos a los jóvenes que fueran beneficiarios del apoyo financiero de los servicios sociales de su municipio $^{47}$.

58. Del mismo modo, Finlandia ha realizado este tipo de combinación de acciones estatales y locales:

a. La Garantía Juvenil entró en vigor a principios de 2013 para garantizar que todos los jóvenes menores de 25 años y todos los jóvenes graduados menores de 30 años se beneficien de un período de prácticas estudiantil, profesional o de readaptación, a más tardar tres meses después del inicio de la situación de desempleo El proyecto clave

\footnotetext{
${ }^{46}$ Un balance de la situación del empleo en este país en CEDS: Conclusiones 2017, Islandia (Artículo 1 derecho al trabajo -§1-, política de pleno empleo; https://hudoc.esc.coe.int).

$4729^{\circ}$ Informe de Islandia sobre el cumplimiento de la CSE, 22 de septiembre de 2016, RAP/RCha/ICE/29(2016), $\quad$ pp. $\quad 11-12 \quad$ y $14-15$ (https://rm.coe.int/CoERMPublicCommonSearchServices/DisplayDCTMContent?documentId=09000016 806ac9ea), y $30^{\circ}$ informe de Islandia sobre el cumplimiento de la CSE, 22 de septiembre de 2017, RAP/RCha/ICE/30(2017), p. 83 (https://rm.coe.int/30th-national-report-from-iceland/168075a488).
} 
consiste en profundizar en la cooperación entre el sector público, el sector privado y el tercer sector brindando apoyo a los jóvenes. El objetivo es reunir las mejores prácticas municipales y ampliar los modelos funcionales a nivel nacional. El Centro One-StopGuidance (Ohjaamo) desempeña un papel importante al agrupar servicios multisectoriales (formación, empleo y readaptación) destinados a jóvenes en un solo punto de servicio y ofreceré así apoyo individualizado a jóvenes de 15 a 29 años que no tengan empleo ni estén cursando estudios ${ }^{48}$.

b. Otra buena práctica para combatir la pobreza y la exclusión social relacionada con el desempleo fue llevada a cabo por el gobierno finlandés entre 2012 y 2015 . Se trató de una experiencia de empleo municipal que incluyó 26 proyectos y 65 municipios. El objetivo era reducir el desempleo estructural mediante la búsqueda de nuevos modelos de integración en el mercado laboral basados en partenariados locales. Al planificar los servicios de promoción del empleo, estos modelos tomaban cada vez más en cuenta las necesidades de demandantes de empleo en paro y de los mercados laborales locales. De manera polivalente, la experiencia municipal ha permitido rehabilitar y activar los servicios municipales para promover el empleo de personas desfavorecidas en el mercado laboral ${ }^{49}$.

\subsection{Acceso de la juventud a la vivienda}

\subsubsection{En general}

59. El difícil acceso de los jóvenes a la vivienda está estrechamente relacionado con los cambios en la juventud y su naturaleza plural, puesto que su situación laboral (y, en consecuencia, sus posibilidades económicas y financieras) difiere según el nivel de estudios y los territorios en cada país. A título de ejemplo, "Francia es uno de los Estados miembros de la Unión Europea en donde la salida del hogar paterno es más prematura. Pero también es uno de los países en los que la vida fuera del hogar paterno recibe más ayudada por parte de la familia, estando la permanencia en el domicilio paterno más bien relacionada con la precariedad del empleo" ${ }^{50}$.

60. Ante esta situación plural, las autoridades francesas han cambiado el marco jurídico en materia de vivienda: definición de los criterios de una vivienda digna (Decreto $\mathrm{N}^{\mathrm{o}}$ 2002-120 de 30 de enero de 2002), implementación de un plan de emergencia para

\footnotetext{
${ }^{48}$ La idea es crear unos cuarenta centros Ohjaamo en diferentes partes del país: $12^{\circ}$ informe de Finlandia sobre el cumplimiento de la CSE, 28 de octubre de 2016, RAP/RCha/FIN/12(2017), p. 60 (https://rm.coe.int/CoERMPublicCommonSearchServices/DisplayDCTMContent?documentId=09000016 $806 \mathrm{c} 2 \mathrm{fb} 0)$.

${ }^{49}$ Ibidem, p. 59.

${ }^{50}$ Le logement autonome des jeunes [El alojamiento autónomo de los jóvenes], Dictamen del Consejo econóomico, social y ambiental (presentado por Claire Guichet, ponente en nombre de la sección de ordenación sostenible del territorio), Legislatura 2010-2015 - Sesión de 23 de enero de 2013: https://www.lecese.fr/sites/default/files/pdf/Avis/2013/2013_06_logement_autonome_jeunes.pdf (visitado el 6 de septiembre 2018), p. 9.
} 
prevención de desahucios (Circular $\mathrm{N}^{\circ}$ UHC/DH2 No 2004-10 de 13 de mayo de 2004) o reconocimiento de un derecho a la vivienda exigible (Ley "DALO" -droit au logement opposable- № 2007-290 de 5 de marzo de 2007) ${ }^{51}$. Más específicamente, en relación con las medidas que deberían favorecer el acceso de la juventud a la vivienda, se han flexibilizado, entre otros aspectos, las condiciones de alquiler a favor de estudiantes y aprendices para poder subarrendar ${ }^{52}$.

61. En Finlandia, cabe subrayar la adopción, en febrero de 2008, del Programa gubernamental "Lo primero, la vivienda", el cual se dirigía a reducir el número de personas sin hogar a largo plazo, con el objetivo básico de reducirlo a la mitad en el horizonte del 2011. En cualquier caso, el programa no solo logró, sino que superó dicho objetivo $^{53}$, lo que condujo al Comité Europeo de Derechos Sociales (CEDS) a considerar que Finlandia seguía comprometida en la lucha contra el fenómeno del sinhogarismo, tal como exige el artículo $31 \S 2$ de la Carta Social ${ }^{54}$. En virtud de dicho programa, la solución de los problemas sociales y de salud no puede ser una condición previa para obtener una vivienda; por el contrario, la vivienda debe ser un requisito previo para solucionar otros problemas que afectan a las personas sin hogar. Tener un lugar para vivir le permite a una persona desarrollar su capacidad para hacer frente a la vida cotidiana y predispone para una actividad más voluntaria ${ }^{55}$. El programa prevé una subvención específica para cubrir la contratación del personal requerido para proporcionar servicios de apoyo y, de este modo, llevar a cabo los proyectos aprobados. Además, los proyectos administrados por los municipios son financiados por el Estado al $50 \%$ de los costes salariales ${ }^{56}$.

\subsubsection{Situaciones de vulnerabilidad}

62. Con respecto al acceso a la vivienda de los jóvenes en situación vulnerabilidad (por ejemplo, migrantes, personas de etnia gitana o de vida itinerante), el fenómeno se revela complejo a la luz de la diversidad de los modos de vida existentes en cada país.

51 Fiche pays - La France et la Charte sociale européenne, p. 13 (https://rm.coe.int/CoERMPublicCommonSearchServices/DisplayDCTMContent?documentId=09000016 80492947).

${ }^{52}$ Le logement autonome des jeunes [El alojamiento autónomo de los jóvenes], Dictamen del Consejo econóomico, social y ambiental de 23 de enero de 2013 (supra), p. 12.

${ }^{53}$ Véanse FEANTSA: "Finland: target of halving long-term homelessness reached", 31 de marzo de 2011, FEANTSA Flash Newsletter, 31 de marzo de 2011 (http://www.feantsa.org,), así como Association for Innovative Social research and Social Planning: "Finland 2010: The Finnish National Programme to reduce long-term homelessness", Synthesis Report (www.peer-review-socialinclusion.eu). Las cifras disponibles más recientes (2018) indican que Finlandia (con 5.5 millones de habitantes) es el único país de Europa que ha disminuido el número de personas sin hogar, año tras año. De 18.000 personas sin domicilio fijo (SDF) hace diez años, el país ha pasado a menos de 7.000, es decir, el 0.14\% de la población.

${ }^{54}$ Conclusiones 2011, Finlandia, Artículo 31 (derecho a la vivienda, apartado 2 - Reducción del número de personas sin hogar, https://hudoc.esc.coe.int).

55 Tannio, Hannele, y Fredriksson, Peter: "The Finnish Homelessness Strategy: From a 'Staircase' Model to a 'Housing First' Approach to Tackling Long-Term Homelessness", European Journal of Homelessness, Volumen 3, diciembre de 2009, pp. 181-199.

${ }^{56}$ Más informaciones sobre dicho progrrama en Pleace, Nicholas : Le logement d'abord, Observatoire européen sur le sans-abrisme, 2014 (https://www.gouvernement.fr/sites/default/files/contenu/piecejointe/2014/09/dihal_hl_etude_feantsa_nicholas_pleace.pdf). 
63. En Noruega, se han adoptado varias medidas prácticas para ayudar a los extranjeros a encontrar vivienda, tales como la introducción de cuotas para beneficiarse del parque inmobiliario existente para refugiados e inmigrantes, la promoción de investigación sobre entornos de vida multiculturales y difusión de información sobre los textos legales que regulan la no discriminación en el acceso a la vivienda ${ }^{57}$.

64. En Irlanda ${ }^{58}$, numerosas entidades locales que han abordado la cuestión de las áreas de tránsito en el marco de los programas de alojamiento de las personas itinerantes para el período 2014-2018, han informado acerca de la falta de solicitudes de uso de estas áreas. Por tal motivo, las autoridades irlandesas han adoptado una serie de medidas:

a. Se destacó el papel de los Comités Consultivos Locales en la acogida de personas itinerantes (Travellers) ${ }^{59}$. Además, cada año se presenta un estudio al Comité Nacional Consultivo de Acogida de Personas Itinerantes (NTACC - National Traveller Accommodation Consultative Committee), en cuya composición tres miembros representan a las organizaciones de personas itinerantes.

b. El Gobierno otorgó el estatuto de Organismo de Vivienda de Utilidad Pública (Approved Housing Body) a la asociación CENA (Asociación para la promoción de viviendas culturalmente adaptadas) en octubre de 2013. Este es el primer organismo oficial de la vivienda dirigido por un miembro de la comunidad de personas itinerantes ${ }^{60}$. La CENA puede solicitar financiación pública para proyectos en materia de vivienda y recibe apoyo administrativo y financiero del Estado.

c. En diciembre de 2015, la Dirección Nacional para la Gestión de Incendios y Emergencias (NDFEM) lanzó un programa de estudio de la seguridad contra incendios en alojamientos locales destinados a personas itinerantes.

\footnotetext{
${ }^{57}$ Fiche pays - La Norvège et la Charte sociale européenne, p. 7: Artículo 19\$4-derecho a la igualdad de trato en materia de acceso a la vivienda (https://rm.coe.int/1680492958).

$5815^{\circ}$ informe de Irlanda sobre el cumplimiento de la CSE, 31 de octubre de 2017, RAP/RCha/IRL/15(2018), p. 4-6 (https://rm.coe.int/15th-simplified-report-of-ireland-on-follow-up-of-ccin-2017/168078245e).

${ }^{59}$ Los Comités Consultivos Locales de acogida de personas itinerantes (LTACC) desempeñan un papel clave en la gestión de las estructuras de alojamiento destinada a dichas personas y en la solución de problemas generados a escala local, especialmente las condiciones de alojamiento, las cuestiones relativas a la salud y a la seguridad, y las áreas de acogida. De una manera general, tienen como función aconsejar a las entidades locales sobre la oferta y la gestión de las estructuras habitacionales destinadas a las personas itinerantes, así como hacer de enlace entre ellas, los miembros y los funcionarios de la corporación local. Un cuarto al menos de los miembros de los LTACC son personas itinerantes de la localidad y representantes de dicha comunidad.

${ }^{60}$ Con ese mismo espíritu, en su Resolución 366(2014) "Empoderar a la juventud de etnia gitana a través de la participación: diseñar políticas efectivas a nivel local y regional", el Congreso invita a las entidades locales y regionales a "comprometerse públicamente a trabajar con la juventud de etnia gitana y sus organizaciones para mejorar su acceso a los derechos sociales; (...) reclutar maestros romaníes y asistentes pedagógicos; (...) reclutar mediadores de etnia gitana para ofrecer asesoramiento sobre la orientación profesional".
} 


\subsection{La lucha contra la discriminación basada en el género y otros estereotipos discriminatorios en la juventud}

65. Resulta paradójico que, en la actualidad, a pesar de los progresos realizados en el campo de la educación (nuevos métodos pedagógicos, trabajo cooperativo, nuevas tecnologías, etc.), la discriminación por razón de género siga siendo una preocupación acuciante en nuestras sociedades. De hecho, los tradicionales estereotipos machistas siguen lamentablemente vigentes entre los jóvenes del conjunto de los Estados miembros del Consejo de Europa.

66. Recordemos las acciones llevadas a cabo en España el 8 de marzo de 2018 con motivo del Día Internacional de los Derechos de la Mujer (huelgas de metros y de trenes, piquetes ante grandes almacenes, presentadores estrella que se ausentaron de los medios de comunicación, etc.) en el marco de una huelga general "feminista" (destinada a denunciar el acoso y la violencia de los que son víctimas las mujeres, o la discriminación salarial) sin precedentes en el país.

67. El rico abanico de buenas prácticas en este ámbito (números de teléfono de emergencia para proteger a las mujeres víctimas de delitos relacionados con el género, capacitación de jueces, instituciones mediadoras contra la discriminación, etc. ${ }^{61}$ nos interpela con toda fuerza al mostrarnos la importancia de la educación (del conjunto de la población) y de la formación (de los profesionales interesados) permanentes no sexistas ${ }^{62}$.

68. Los estereotipos sobre los roles tradicionales explican en gran medida el espectro limitado de opciones profesionales para las mujeres y las barreras que afrontan en sus carreras. Para abordar este problema, el Gobierno Federal alemán ha lanzado una serie de iniciativas, por ejemplo:

a. los proyectos "Zukunft für Mädchen und Jungen" ("Día de las niñas y Día de los niños") desde 2011;

b. el proyecto nacional "Neue Wege fürs Jungs" ("Nuevas vías para los niños"), desde 2005 ;

c. "National Kooperationen zur Berufs- und Studienwahl frei von Geschlechterklischees" ("Cooperaciones nacionales para opciones profesionales y cursos universitarios libres de clichés de género", desde 2016: www.klischee-frei.de);

\footnotetext{
${ }^{61}$ Véase Comisión para la igualdad de género, Compilation de bonnes pratiques en matière d'accès à la justice pour les femmes, Conseil de l’Europe, 2015, 136 páginas.

${ }^{62}$ Véase Commisión para la igualdad de género, Compilation of good practices to combat sexism in Council of Europe member states, Document d'ilnformation (révisé 2), Strasbourg, 4 de junio 2018, 47 páginas (https://rm.coe.int/compilation-of-goodpractices-to-prevent-and-combat-sexism-revised/16808b15a5). 
d. la iniciativa "MINT Zukunft schaffen" ("Crear MINT Future" - MINT: Matemáticas, Informática, Ciencias Naturales, Tecnología), así como la etiqueta TOTAL-EQUALITY ${ }^{63}$.

69. En el mismo contexto, otras buenas prácticas hacen frente a casos de acoso sexual en la vida laboral, la mayoría de los cuales tienen como víctimas a mujeres jóvenes $(\text { Suecia })^{64}$.

70. La lucha contra las diferencias salariales (más acentuadas en perjuicio de las mujeres jóvenes que encuentran su primer puesto de trabajo) también ha conocido progresos en la práctica (Islandia) ${ }^{65}$ a medida que se han ido produciendo mejoras normativas y jurisprudenciales (algunos países han adaptado su legislación a la jurisprudencia del CEDS, a fin de no imponer comparaciones de remuneración dentro de la misma empresa, sino permitir comparaciones entre varias empresas) ${ }^{66}$.

71. Incluso las actividades recreativas quedan expuestas a la violencia sexista. Para combatir esta plaga, la instalación de "puntos morados" (el color tradicional del feminismo) se ha introducido en España como una buena práctica. Estos puntos constituyen espacios de información y de denuncia contra cualquier acto de discriminación basada en el sexo con respecto a mujeres jóvenes en festivales y otros eventos y fiestas populares.

72. Análogas buenas prácticas se revelan necesarias para luchar contra otros estereotipos discriminatorios entre los jóvenes, incluidos los relacionados con la orientación sexual, la identidad de género, la expresión de género o la diversidad corporal: por ejemplo, en Bélgica, se han implementado diversas medidas de apoyo y sensibilización para combatir los estereotipos y los clichés homofóbicos y transfóbicos entre los jóvenes. Tales medidas incluyen la creación de un centro de información por parte de la Comunidad flamenca

$6335^{\circ}$ informe de Alemania sobre el cumplimiento de la CSE, 28 de diciembre de 2017, RAP/RCha/DEU/35(2018), p. $24 \quad$ (https://rm.coe.int/35th-report-from-the-goverment-ofgermany/1680779fb6).

${ }^{64}$ Entre 2013 y 2016, el Defensor del Pueblo sueco en materia de discriminación (DO) recibió 117 quejas sobre acoso sexual en el trabajo. La mayor parte de dichas quejas (99) fueron presentadas por mujeres. La mayoría de los casos involucraron a mujeres jóvenes que habían sido víctimas de acoso sexual por un hombre que ocupaba un puesto superior en su lugar de trabajo: $17^{\circ}$ informe de Suecia sobre el cumplimiento de la CSE, 24 de octubre de 2017, RAP/RCha/SWE/17(2018), p. 19 (https://rm.coe.int/17th-report-fromthe-government-of-sweden/168077e399).

${ }^{65}$ El 1 de enero de 2018 entró en vigor en Islandia una nueva legislación para prohibir las diferencias salariales entre hombres y mujeres. Desde entonces es ilegal pagarle a un hombre más que a una mujer en empresas que emplean al menos a 25 personas asalariadas (obligación de obtener un certificado oficial que acredite su política de igualdad de remuneración). El incumplimiento de dicha igualdad salarial se castiga con una multa.

${ }^{66}$ CEDS: Observación interpretativa sobre el artículo 20 de la Carta Social revisada de 1996/Artículo 1 del Protocolo adicional de 1988: Comparaciones sobre igualdad de remuneración, Conclusiones 2012, enero de 2013 (https://hudoc.esc.coe.int). 
(www.transgenderinfo.be) ${ }^{67}$ o la campaña de sensibilización “Et toi t’es casé-e” “¿Y tú, estás encasillado-a?" (www.ettoitescase.be/) ${ }^{68}$.

73. Una educación a una edad temprana es necesaria para evitar que los niños y adolescentes se impregnen de esos estereotipos discriminatorios. Un ejemplo de buena práctica: la decisión del Gobierno croata de retirar un libro de texto de biología que contenía manifestaciones discriminatorias por razón de orientación sexual, con lo cual se daba cumplimiento a una decisión del $\operatorname{CEDS}^{69}$.

74. Sin embargo, la educación (formal o no formal) por sí sola no es suficiente para prevenir y combatir los estereotipos discriminatorios. Desde este punto de vista, la educación informal en sentido amplio incluye el importante papel de los medios de comunicación en este ámbito. En Bélgica, por ejemplo, la guía de buenas prácticas lanzada por la Asociación de Periodistas Profesionales (con la colaboración de la Federación Valonia-Bruselas) pretendió deconstruir las ideas recibidas sobre estereotipos negativos ligados a prácticas periodísticas existentes en Bélgica y en el extranjero en materia de representación y de participación de los jóvenes en los medios de comunicación. Una de las iniciativas, "Let's Talk Young" ("Parlons Jeunes"/ "Hablemos en clave juvenil", en colaboración con el diario gratuito Métro, que publicaba las colaboraciones juveniles en el sitio web: www.enlignedirecte.be), tenía como objetivo experimentar la profesión periodística dando la palabra a grupos de jóvenes con horizontes diversos, pero todos reunidos en torno a un tema por edición (pobreza, participación política, etc. $)^{70}$.

\subsection{Un desafío: mejorar el acceso a los derechos sociales y combatir el no recurso o la dificultad para recurrir}

75. La sensibilización de los jóvenes sobre sus derechos y la forma de ejercerlos también implica, para esta problemática transversal, la existencia de procedimientos accesibles de mediación y jurisdiccionales ${ }^{71}$. Las obligaciones positivas de los poderes públicos en términos de sensibilización se revelan tanto más importantes cuanto que los jóvenes potencialmente beneficiarios a menudo no son conscientes de ello; Paradójicamente,

67 Con una línea telefónica gratuita (0800 96 316) y una dirección de correo electrónico (contact@transgenderinfo.be): 11 $1^{\circ}$ informe de Bélgica sobre el cumplimiento de la CSE, 27 de octubre de 2016, RAP/RCha/BEL/11(2017), $\quad$ p. 49 (https://rm.coe.int/CoERMPublicCommonSearchServices/DisplayDCTMContent?documentId=09000016 806c2fae).

${ }^{68}$ En dicha web puede encontrarse una Guía pedagógica (destinada a profesionales de los sectores educativo, deportivo y de la juventud), fichas pedagógicas, videoclips y anuncios de televisión.

${ }^{69}$ Decisión de fondo de 30 marzo de 2009 (Reclamación № 45/2007, Interights c. Croacia, Artículo $11 \S 2$ CSE).

${ }^{70}$ La presse quotidienne et les jeunes. Un «Guide de bonnes pratiques 》 à l'usage des jeunes et des journalistes, AJP, 2015 (http://www.ajp.be/bonnespratiques/), p. 11-12.

${ }^{71}$ En la Resolución 334(2011) Desarrollando indicadores para la sensibilización en derechos humanos a nivel local y regional, el Congreso insta a "contribuir a fomentar la creación, en los niveles local y regional, de mecanismos independientes de recurso tales como los mediadores locales". 
aquellos que no siempre cumplen las posibles condiciones de ejercicio sí son conocedores de ello.

76. Mencionemos algunas medidas recientes adoptadas en Francia en este ámbito ${ }^{72}$ :

a. La simplificación de la domiciliación administrativa de las personas sin domicilio estable (la cual permite disponer de una dirección para recibir correo, pero especialmente para acceder a ciertos derechos y beneficios sociales);

b. En la lucha contra las dificultades para recurrir (el no recurso), la "cita con los derechos" ("rendez-vous des droits") tuvo un éxito rápido: desde su puesta en marcha en 2013, se han realizado más de 650.000 citas con los derechos;

c. Una herramienta de simulación de derechos (https://mes-aides.gouv.fr/), así como un portal digital de derechos sociales (https://www.mesdroitssociaux.gouv.fr/) y cientos de puntos de mediación digital en el territorio ha sido abiertos a los usuarios para facilitar sus trámites;

$d$. Se ha puesto en práctica asimismo una experiencia con algunos centros municipales de acción social para el establecimiento de una caja fuerte digital que permita a las personas beneficiaras el poder conservar todos los documentos necesarios para el ejercicio de los diversos derechos sociales;

e. La desmaterialización de los derechos y los intercambios de flujos no impiden el apoyo humano necesario para las personas más excluidas;

f. La modernización de las prácticas profesionales de los trabajadores sociales y el fortalecimiento de sus habilidades (incluido el uso de tecnología digital) mejoran el acceso a los derechos de las personas beneficiarias.

\section{CONCLUSIONES}

77. Los derechos sociales de la juventud encuentran en la Carta Social Europea su fuente jurídica vinculante más emblemática para enmarcar las sinergias con los otros instrumentos y mecanismos del Consejo de Europa en este terreno, y en particular las actividades e iniciativas del Congreso y del Sector de la Juventud ${ }^{73}$.

78. Los poderes locales y regionales, así como los interlocutores sociales y las organizaciones de la sociedad civil, desempeñan un papel esencial tanto en la difusión de

$7217^{\circ}$ informe de Francia sobre el cumplimiento de la CSE, 29 de noviembre de 2017 , RAP/RCha/FRA/17(2018), supra, pp. 15-17.

${ }^{73}$ Véase también la Semana Europea de la Juventud Enter!, Estrasburgo, 1-5 de julio de 2019, un evento organizado como parte del $70^{\circ}$ aniversario del Consejo de Europa (http://70.coe.int/home/).

ISSN: 2174-6419

Lex Social, vol. 10, núm. 1 (2020) 
la Carta Social como en su puesta en práctica para facilitar el acceso y el ejercicio por parte de los jóvenes de los derechos sociales en ella reconocidos. Ese papel crucial de las autoridades locales y regionales para hacer que la Carta Social sea efectiva en el plano jurídico (de acuerdo con las competencias "sociales" que forman parte del núcleo de su respectiva autonomía) merece el apoyo de programas y planes de acción nacionales, europeos e internacionales.

79. La Carta Social no constituye únicamente un vector de protección de los derechos sociales de la juventud (como beneficiarios o titulares), sino asimismo una plataforma que se beneficia del potencial papel activo de las y los jóvenes. Gracias a los valores que representa (igualdad, solidaridad, inclusión social, participación), la Carta Social, como Pacto europeo por la democracia social o Constitución social de Europa, puede beneficiarse del dinamismo y el liderazgo de la juventud.

80. A los Estados miembros que aún no lo hayan hecho, se les debería invitar a aceptar, en el espíritu del "Proceso de Turín", el procedimiento de reclamaciones colectivas y la Carta Social Europea revisada. El cumplimiento de la Carta Social y de la jurisprudencia del CEDS ofrecen, en efecto, una amplia gama de buenas prácticas referentes al acceso y al ejercicio de los derechos sociales por parte de la juventud y, en consecuencia, constituyen una fuente importante de inspiración para las acciones locales y regionales en dicho ámbito.

81. Las entidades locales y regionales, por su parte, deben implicarse tanto en el momento de la elaboración de los informes nacionales anuales (o en el de la preparación de las observaciones sobre posibles reclamaciones colectivas) presentados al CEDS por los gobiernos de los Estados partes, como en el momento de proceder a la ejecución de las conclusiones y decisiones del Comité. Esta implicación es coherente con el artículo 4.6 de la Carta Europea de Autonomía Local, que prevé la consulta a las entidades locales "a lo largo de los procesos de planificación y de decisión para todas las cuestiones que les afectan directamente". En su condición de tratado "emblemático" del Consejo de Europa en el campo de los derechos sociales, la Carta Social se erige también en motor para la inclusión social y la participación activa de la juventud en la vida de la comunidad, cuyo dinamismo proviene esencialmente de los niveles locales y regionales.

82. Se recomienda que se desarrollen planes de acción para sensibilizar en materia de derechos sociales de la juventud a escalas local y regional, a través de programas de formación y de intercambio de las mejores prácticas entre representantes electos y líderes de la juventud ${ }^{74}$. En el marco de tales formaciones e intercambios, el conocimiento de la

\footnotetext{
${ }^{74}$ Los líderes de la juventud son voluntarios o profesionales implicados en un trabajo o una acción con y para jóvenes en una variedad de entornos: organizaciones juveniles, servicios de juventud, centros juveniles, centros de formación de animadores de juventud o de trabajadores sociales, o cualquier otra estructura que actúe en el ámbito de la educación no formal de la juventud ("Glosario" - Anexo a la Recomendación CM/Rec(2015)3 del Comité de Ministros a los Estados miembros sobre el acceso de la juventud de los barrios desfavorecidos a los derechos sociales).
} 
Carta Social (las buenas prácticas relacionadas con cumplimiento y con la jurisprudencia del CEDS) ocuparía un lugar primordial en el espíritu de la Resolución 334 (2011) del Congreso "Desarrollo de indicadores para la sensibilización en derechos humanos a nivel local y regional". Dichas actividades podrían organizarse en colaboración con las asociaciones o federaciones nacionales que representan a las entidades territoriales y con ocasión de los procesos de consulta mencionados anteriormente.

83. En cuanto a la promoción de la Carta Social, se debe invitar a las autoridades locales y regionales a difundir el texto de la Carta Social en el sitio web de cada entidad local o regional. Desde esta perspectiva, sería interesante diseñar una versión adaptada o "fácil de usar" (accesible en línea) de la "Carta Social explicada a los jóvenes" (o "El lugar de la juventud en la Carta Social Europea") ${ }^{75}$.

84. Actividades tales como un concurso para redactar e ilustrar esa versión adaptada podrían organizarse a escala local y/o regional. Dicha versión también serviría como guía para la acción normativa, política y financiera de los representantes electos locales y regionales, lo que les permitiría disponer de una especie de estudio de "impacto en la juventud". Esta versión configuraría asimismo un instrumento "transversal" que facilitaría el acceso de la juventud a sus derechos y, por lo tanto, mejoraría su capacidad para ejercerlos a diario.

85. Las entidades locales y regionales pueden igualmente desarrollar acciones concretas relacionadas con el ejercicio de algunos derechos sociales por parte de las y los jóvenes, tales como medidas de apoyo activo al empleo, acciones en materia de educación sanitaria, prevención de la violencia de género entre las y los jóvenes, que podrían ser difundidas y promovidas por las redes sociales (utilizadas cotidianamente por la juventud). Semejantes difusión y promoción (en línea y eventualmente cara a cara) serían idóneas para estimular la participación y el compromiso de los jóvenes a favor de los derechos sociales.

86. En dicho cometido, también deben realizarse inversiones para mejorar el acceso público a las tecnologías de la información a través de los servicios públicos existentes (centros juveniles, bibliotecas públicas, videotecas, centros de información y orientación juvenil, etc.), en el espíritu de la Recomendación del Comité de Ministros $\mathrm{CM} / \operatorname{Rec}(2015) 3$ sobre el acceso de la juventud de los barrios desfavorecidos a los derechos sociales.

87. Finalmente, es esencial invertir en generar conciencia sobre los derechos sociales de la juventud. Esto puede hacerse a través de iniciativas tales como la celebración, en cada

\footnotetext{
${ }^{75}$ Véase el ejemplo del folleto (en formato de "tebeo") Dime, ¿qué es la Carta Social Europea? (2011), elaborado por el Servicio de la Carta Social Europea con motivo del 50 aniversario de la Carta de 1961: https://rm.coe.int/CoERMPublicCommonSearchServices/DisplayDCTMContent?documentId=09000016 $8047 \mathrm{e} 17 \mathrm{~d}$
} 
comunidad local y regional, del Día Internacional de la Juventud (12 de agosto) o del Día de la Carta Social Europea (18 de octubre). Tales iniciativas podrían ser una oportunidad para que las entidades locales y regionales alentaran a los Estados que aún no lo hayan hecho a aceptar la Carta Social Revisada de 1996 y el procedimiento de reclamaciones colectivas, de tal manera que la Carta Social y su mecanismo de reclamaciones sean concebidos como espacios de sensibilización en donde no únicamente las autoridades públicas (por ejemplo, los servicios sociales), sino especialmente los propios jóvenes, mostrarían un aumento de su solidaridad y una mayor implicación en la defensa de sus derechos sociales (especialmente con respecto a las y los jóvenes en una situación más vulnerable, como estar en paro, ser migrantes, tener alguna discapacidad, etc.).

\title{
5. ANEXOS. RESOLUCIÓN 442(2019) Y RECOMENDACIÓN 443 (2019) DEL CONGRESO DE PODERES LOCALES Y REGIONALES ${ }^{76}$
}

\subsection{Resolución 442(2019) del Congreso de Poderes Locales y Regionales}

\author{
RESOLUCIÓN 442 (2019) $)^{77}$
}

1. Los derechos sociales fundamentales de los ciudadanos de los Estados miembros del Consejo de Europa están garantizados por la Carta Social Europea (STE N ${ }^{\circ}$ 163, en adelante, la "Carta Social"), que se abrió a la firma de los Estados miembros en 1961, entró en vigor en 1965 y luego fue revisada en 1996.

2. Se trata de un documento de orientación esencial que establece las normas básicas de los derechos sociales y económicos fundamentales a nivel paneuropeo. Garantiza un amplio abanico de derechos humanos cotidianos relacionados con el empleo, la vivienda, la salud, la educación, la protección social y el bienestar. La Carta Social menciona explícitamente la juventud como titular de derechos sociales en materia de educación y de inserción en el mercado laboral, o la ayuda a los hogares jóvenes.

3. Con objeto de desarrollar directrices concretas para facilitar el cumplimiento de los derechos reconocidos en la Carta Social, en particular en lo que afecta a la juventud, lasa diversas instancias del Consejo de Europa ha adoptado a lo largo de la última década una

\footnotetext{
${ }^{76}$ GC36(2019)12final. Co-ponentes: Liisa ANSALA, Finlandia (L, GILD) y Piero FASSINO, Italia (L, SOC).

L: Cámara de los Poderes Locales / R: Cámara de las Regiones. PPE/CCE: Grupo del Partido Popular Europeo del Congreso; SOC: Grupo Socialista; GILD: Grupo Independiente Liberal y Democrático; CRE: Grupo de los Conservadores y Reformistas Europeos; NI: Miembro no perteneciente grupo político alguno del Congreso.

${ }^{77}$ Debate y adopción por el Congreso el 3 de abril de 2019, 2a sesión (véase el documento CG36(2019)12, exposición de motivos o memorando explicativo), Co-ponentes: Liisa ANSALA, Finlandia (L, GILD) y Piero FASSINO, Italia (L, SOC).
} 
serie de textos, los cuales han puesto de manifiesto da responsabilidad de los poderes públicos para facilitar el acceso de la juventud a los derechos fundamentales.

4. Las recomendaciones de la Asamblea Parlamentaria del Consejo de Europa sobre "El acceso de la juventud a los derechos fundamentales" (2015(2013)) y "Hacia una Convención Marco Europea sobre los derechos de la juventud" (1978(2011)) ${ }^{78}$, así como la Recomendación del Comité de Ministros CM/Rec(2016)7 sobre "El acceso de la juventud a los derechos", han suministrado la ocasión para subrayar que no es necesario adoptar un tratado específico en materia de derechos de la juventud, sino más bien explotar los instrumentos vinculantes que ya existen y tomar medidas que faciliten el acceso de la juventud a los derechos fundamentales enunciados en el Convenio Europeo de Derechos Humanos (en adelante "CEDH") y en la Carta Social revisada.

5. El Servicio de la Juventud del Consejo de Europa elabora directrices, programas e instrumentos jurídicos para la puesta en marcha de políticas de juventud coherentes y efectivas, así como herramientas concretas, tales como "La autoevaluación de las políticas de juventud". De conformidad con la Recomendación CM/Rec(2015)3 del Comité de Ministros sobre el acceso de la juventud de los barrios desfavorecidos a los derechos sociales, se deben realizar estudios periódicos sobre las medidas tomadas por los Estados miembros, pero también sobre los proyectos e iniciativas puestas en práctica por organizaciones de la juventud y por las entidades locales y regionales.

6. La aplicación de la Carta Social y la jurisprudencia del Comité Europeo de Derechos Sociales ofrecen una amplia gama de buenas prácticas sobre el acceso y el ejercicio de los derechos sociales de juventud y, por consiguiente, constituyen una fuente de inspiración para acciones locales y regionales en este ámbito.

7. Los poderes locales y regionales, así como los interlocutores sociales y las organizaciones de la sociedad civil, desempeñan un papel esencial tanto en la difusión de la Carta Social como en su puesta en práctica, con miras a garantizar el acceso y el ejercicio de los derechos sociales por parte de la juventud. Ese papel crucial de las entidades locales y regionales para hacer que la Carta Social sea efectiva en el plano jurídico (en línea con las competencias "sociales" que se enmarcan en su respectiva autonomía) merece ser apoyado a través de programas y planes de acción nacionales, europeos e internacionales.

8. El Congreso de Poderes Locales y Regionales del Consejo de Europa (en adelante "el Congreso"), mediante la elaboración de resoluciones y otros instrumentos tendentes a

\footnotetext{
${ }^{78}$ La Recomendación de la Asamblea Parlamentaria 1978(2011) "Hacia una Convención Marco Europea sobre los Derechos de la Juventud" brindó la oportunidad para una reflexión interesante que confirmó que no resulta necesario adoptar un tratado específico sobre los derechos de la juventud, sino más bien explotar los instrumentos vinculantes ya existentes en la Organización: su principio 7.1 invita a los Estados Miembros a "tomar medidas que faciliten el acceso de la juventud a los derechos fundamentales consagrados en el Convenio Europeo de Derechos Humanos y en la Carta Social Europea (revisada)". 
reforzar la integración, la participación y el compromiso de los jóvenes en los niveles local y regional, ahora desea ahora poner el acento en los derechos sociales de la juventud garantizados por la Carta Social, con el fin de dar una expresión concreta a los derechos de la juventud y garantizar su cumplimiento.

9. El Congreso asocia a los delegados jóvenes a sus propios trabajos desde 2014 invitando a jóvenes procedentes de diferentes horizontes a participar en sus sesiones, a dar su punto de vista en el curso de los debates y a mantener intercambios con los miembros del Congreso. En 2015, con ocasión de la 29a sesión del Congreso, los delegados jóvenes presentaron una proposición de resolución sobre "La promoción por parte de las entidades locales y regionales del acceso de la juventud a los derechos sociales"79, llamando la atención sobre el hecho de que el acceso a una educación de calidad, a un empleo seguro, a condiciones de vida dignas, al transporte, a la atención sanitaria, a las tecnologías y a oportunidades para la participación social, cultural y económica, son condiciones previas para la inclusión y la ciudadanía activa de todas y todos los jóvenes. Subrayaron asimismo el carácter útil de crear un conjunto de herramientas para las entidades locales tendentes a facilitar el acceso de la juventud a sus derechos, proponiendo buenas prácticas y un enfoque general de los instrumentos políticos relevantes.

10. A la luz de lo anterior e inspirándose en los trabajos del Congreso sobre la dimensión de los "derechos humanos" a nivel local, así como en el debate organizado por la Cámara de las Regiones sobre la puesta en práctica de los derechos sociales a nivel regional (2016) y en las propuestas de los delegados jóvenes, el Congreso recomienda a las entidades locales y regionales y a las asociaciones que las representan, en el marco de las competencias que se les han sido atribuidas:

a. que ejerzan presión sobre las autoridades nacionales de los Estados miembros que aún no lo hayan hecho para que firmen y ratifiquen la Carta Social Europea revisada (STE ${ }^{\circ}$ 163), y acepten el procedimiento de reclamaciones colectivas, de tal manera que la Carta Social y su mecanismo de reclamaciones sean percibidos como espacios de sensibilización en donde no únicamente las autoridades públicas (por ejemplo, los servicios sociales), sino especialmente los propios jóvenes, mostrarían un aumento de su solidaridad y una mayor implicación en la defensa de sus derechos sociales (especialmente con respecto a las y los jóvenes en una situación más vulnerable, como estar en paro, ser migrantes, tener alguna discapacidad, etc.);

$b$. que difundan el texto de la Carta Social en el sitio Internet de cada entidad local o regional y que diseñen una versión adaptada o "fácil de usar" (accesible en línea) de la "Carta Social explicada a los jóvenes" (o "El lugar de la juventud en la Carta Social Europea"), por ejemplo a través de concursos para redactar e ilustrar esa versión adaptada organizados a escala local y/o regional (dicha versión también serviría como guía para la acción normativa, política y financiera de los representantes electos locales y regionales);

${ }^{79} \mathrm{CG} / 2015(29) 23$. 
c. que consideren los derechos sociales de la juventud como una prioridad de sus políticas y que desarrollen acciones concretas relativas al ejercicio de algunos derechos sociales por parte de las y los jóvenes, tales como medidas de apoyo activo al empleo, acciones en materia de educación sanitaria, prevención de la violencia de género entre las y los jóvenes, las cuales podrían ser difundidas y promovidas por las redes sociales. Semejantes difusión y promoción (en línea y eventualmente cara a cara) serían idóneas para estimular la participación y el compromiso de los jóvenes a favor de los derechos sociales;

$d$. que inviertan para mejorar el acceso público a las tecnologías de la información a través de los servicios públicos existentes (centros juveniles, bibliotecas públicas, videotecas, centros de información y orientación juvenil, etc.), en el espíritu de la Recomendación del Comité de Ministros CM/Rec(2015)3 sobre el acceso de la juventud de los barrios desfavorecidos a los derechos sociales;

e. que generen sensibilización sobre los derechos sociales de la juventud a través de iniciativas tales como la celebración, en cada comunidad local y regional, del Día Internacional de la Juventud (12 de agosto) o del Día de la Carta Social Europea (18 de octubre);

$f$. que participen en el examen que realizará el Servicio de la Juventud del Consejo de Europa en 2019 para evaluar el seguimiento de la Recomendación del Comité de Ministros CM/Rec(2015)3 sobre el acceso de la juventud de los barrios desfavorecidos a los derechos sociales, el cual versará asimismo sobre los proyectos e iniciativas implementados por las entidades locales y regionales.

11. Teniendo en cuenta sus trabajos precedentes, el Congreso recomienda a las entidades locales y regionales que den cumplimiento a las recomendaciones contenidas en sus Resoluciones 414(2017), 386(2015), 346(2012), 319(2010) y 259(2008) ${ }^{80}$.

\footnotetext{
${ }^{80}$ Resolución 414(2017) "¿Eternamente joven? El papel de las políticas de juventud y del trabajo juvenil a nivel local y regional para apoyar la transición de los jóvenes hacia la autonomía y la vida profesional"; Resolución 386(2015) "Adoptar un lenguaje común entre la juventud y las entidades locales para eliminar las barreras a la participación juvenil"; Resolución 346(2012) "Juventud y democracia: la evolución del compromiso político de las y los jóvenes"; Resolución 319(2010), "La integración de la juventud de los barrios desfavorecidos"; Resolución 259(2008), "La integración y la participación de la juventud a nivel local y regional".
} 


\title{
5.2. Recomendación 433(2019) del Congreso de Poderes Locales y Regionales
}

\author{
RECOMENDACIÓN 433 (2019) $)^{81}$
}

1. Los derechos sociales fundamentales de los ciudadanos de los Estados miembros del Consejo de Europa están garantizados por la Carta Social Europea (STE N ${ }^{\circ}$ 163, en adelante, la "Carta Social"), que se abrió a la firma de los Estados miembros en 1961, entró en vigor en 1965 y luego fue revisada en 1996.

2. Se trata de un documento de orientación esencial que establece las normas básicas de los derechos sociales y económicos fundamentales a nivel paneuropeo. Garantiza un amplio abanico de derechos humanos cotidianos relacionados con el empleo, la vivienda, la salud, la educación, la protección social y el bienestar. La Carta Social menciona explícitamente la juventud como titular de derechos sociales en materia de educación y de inserción en el mercado laboral, o la ayuda a los hogares jóvenes.

3. Con objeto de desarrollar directrices concretas para facilitar el cumplimiento de los derechos reconocidos en la Carta Social, en particular en lo que afecta a la juventud, lasa diversas instancias del Consejo de Europa ha adoptado a lo largo de la última década una serie de textos, los cuales han puesto de manifiesto da responsabilidad de los poderes públicos para facilitar el acceso de la juventud a los derechos fundamentales

4. La Recomendación del Comité de Ministros CM/Rec(2016)7 a los Estados miembros sobre "El acceso de la juventud a los derechos" adoptada el 28 de septiembre de 2016, así como las recomendaciones de la Asamblea Parlamentaria del Consejo de Europa sobre "El acceso de la juventud a los derechos fundamentales" (2015(2013)) y "Hacia una Convención marco europea sobre los derechos de la juventud" $(1978(2011))^{82}$, han suministrado la ocasión para subrayar que no es necesario adoptar un tratado específico en materia de derechos de la juventud, sino más bien explotar los instrumentos vinculantes que ya existen y tomar medidas que faciliten el acceso de la juventud a los derechos fundamentales enunciados en el Convenio Europeo de Derechos Humanos (en adelante "CEDH") y en la Carta Social revisada.

5. La aplicación de la Carta Social y la jurisprudencia del Comité Europeo de Derechos Sociales ofrecen una amplia gama de buenas prácticas sobre el acceso y el ejercicio de

\footnotetext{
${ }^{81}$ Debate y adopción por el Congreso el 3 de abril de 2019, 2a sesión (véase el documento CG36(2019)12, exposición de motivos o memorando explicativo), Co-ponentes: Liisa ANSALA, Finlandia (L, GILD) y Piero FASSINO, Italia (L, SOC).

${ }^{82}$ La Recomendación de la Asamblea Parlamentaria 1978(2011) "Hacia una Convención Marco Europea sobre los Derechos de la Juventud" brindó la oportunidad para una reflexión interesante que confirmó que no resulta necesario adoptar un tratado específico sobre los derechos de la juventud, sino más bien explotar los instrumentos vinculantes ya existentes en la Organización: su principio 7.1 invita a los Estados Miembros a "tomar medidas que faciliten el acceso de la juventud a los derechos fundamentales consagrados en el Convenio Europeo de Derechos Humanos y en la Carta Social Europea (revisada)". 
los derechos sociales de juventud y, por consiguiente, constituyen una fuente de inspiración para acciones locales y regionales en este ámbito.

6. Los poderes locales y regionales, así como los interlocutores sociales y las organizaciones de la sociedad civil, desempeñan un papel esencial tanto en la difusión de la Carta Social como en su puesta en práctica, con miras a garantizar el acceso y el ejercicio de los derechos sociales por parte de la juventud. Ese papel crucial de las entidades locales y regionales para hacer que la Carta Social sea efectiva en el plano jurídico (en línea con las competencias "sociales" que se enmarcan en su respectiva autonomía) merece ser apoyado a través de programas y planes de acción nacionales, europeos e internacionales.

7. El Congreso de Poderes Locales y Regionales del Consejo de Europa (en adelante "el Congreso"), mediante la elaboración de resoluciones y otros instrumentos tendentes a reforzar la integración, la participación y el compromiso de los jóvenes en los niveles local y regional, ahora desea ahora poner el acento en los derechos sociales de la juventud garantizados por la Carta Social, con el fin de dar una expresión concreta a los derechos de la juventud y garantizar su cumplimiento.

8. A la luz de lo anterior, se recomienda a los Estados miembros:

a. para aquellos que aún no lo hayan hecho, que firmen y ratifiquen la Carta Social Europea revisada (STE No 163), y acepten, en el espíritu del "Proceso de Turín", el procedimiento de reclamaciones colectivas y la Carta Social Europea revisada, puesto que el cumplimiento de la Carta y de la jurisprudencia del Comité Europeo de Derechos Sociales ofrecen una amplia gama de buenas prácticas referentes al acceso y al ejercicio de los derechos sociales por parte de la juventud y, en consecuencia, constituyen una fuente importante de inspiración para las acciones locales y regionales en dicho ámbito;

$b$. que impliquen a las entidades locales y regionales, tanto en el momento de la elaboración de los informes nacionales anuales (o en el de la preparación de las observaciones sobre posibles reclamaciones colectivas) presentados al Comité Europeo de Derechos Sociales por los gobiernos de los Estados partes, como en el momento de proceder a la ejecución de las conclusiones y decisiones del Comité. Esta implicación es coherente con el artículo 4.6 de la Carta Europea de Autonomía Local, que prevé la consulta a las entidades locales "a lo largo de los procesos de planificación y de decisión para todas las cuestiones que les afectan directamente". En efecto, en su condición de tratado "emblemático" del Consejo de Europa en el campo de los derechos sociales, la Carta Social se erige también en motor para la inclusión social y la participación activa de la juventud en la vida de la comunidad;

$c$. que desarrollen planes de acción nacionales para sensibilizar en materia de derechos sociales de la juventud, en coordinación con los podres locales y regionales y en 
cooperación con los representantes de la juventud, al ser estos últimos voluntarios o profesionales implicados en el trabajo o la acción con y para las y los jóvenes en contextos diferentes, para la difusión de buenas prácticas a todos los niveles de responsabilidad. 